\title{
La transferencia pragmática a través del contacto lingüístico: Las mesetas entonativas del castellano chileno y el mapudungun como mecanismo de extensión del foco discursivo
}

\author{
Brandon M. A. Rogers ${ }^{1}$ \\ Texas Tech University, EE. UU.
}

\begin{abstract}
Resumen
Se ha aseverado que fuera de unos préstamos léxicos, el mapudungun ha tenido poca influencia lingüística en el castellano chileno (p.ej. Alonso 1953). Pese a ello, estudios recientes (p. ej. Sadowsky 2013) indican que el mapudungun puede haber influido en el español chileno de manera más extensa de lo que anteriormente se ha afirmado. La presente investigación analiza un contorno entonativo con forma de meseta anteriormente documentado en Rogers (2013). Se determinó que el mapudungun cuenta con contornos parecidos y que el comportamiento prosódico, sintáctico y pragmático de éstos se asemeja mucho al de los del castellano chileno. Se propone que, en ambas lenguas, estos contornos funcionan como un mecanismo de extensión del foco discursivo y que el mapudungun aportó esta estrategia pragmática a la fonología entonativa del español chileno.

Palabras clave: entonación, mapudungun, español chileno, contacto lingüístico.
\end{abstract}

1 Para correspondencia, dirigirse a: Brandon Rogers (rog65110@ttu.edu), Department of Classical and Modern Languages and Literatures, Texas Tech University, $290618^{\text {th }}$ St., Lubbock, TX 79410, USA. 


\title{
Pragmatic transfer through language CONTACT: CHILEAN SPANISH AND MAPUDUNGUN INTONATIONAL PLATEAUS AS MECHANISMS OF EXTENDED FOCUS
}

\begin{abstract}
Notions that Mapudungun, an Amerindian language spoken in modern-day Chile, has had any linguistic influence on Chilean Spanish outside of lexical loanwords have met stiff resistance (e.g. Alonso 1953). However, recent studies (e.g. Sadowsky 2013) suggest that Mapudungun's influence on Chilean Spanish may have been more profound that previously asserted. The current study examines a unique intonational "plateau" pattern documented in Rogers (2013). Similar patterns occur in Mapudungun and the data demonstrate that Mapudungun intonational plateaus and Chilean Spanish intonational plateaus behave very similarly at different prosodic, syntactic, and pragmatic levels. This study proposes the plateau patterns in both languages are a mechanism of focus extension and that Mapudungun introduced this unique pragmatic device into Chilean Spanish intonational phonology.
\end{abstract}

Keywords: Intonation, Mapudungun, Chilean Spanish, language contact.

Recibido: 14/05/19 Aceptado: 19/06/20

\section{INTRODUCCIÓN}

En términos relativos, el castellano chileno sigue siendo una variedad del español poco estudiada por lingüistas comparada con otras variedades como las de la Ciudad de México, Buenos Aires, Madrid y numerosas regiones de Estados Unidos. Pese a ello, desde una época temprana de la lingüística moderna, se estableció que el castellano hablado en Chile consiste en una variada gama de peculiaridades que se manifiestan en numerosos subsistemas lingüísticos del mismo. Aunque no fue el primero, el alemán Rodolfo Lenz fue el que con mayor eficacia colocó el español de Chile en la vanguardia del debate lingüístico durante su época con su esmerada documentación de un gran número de sus rasgos. También se le considera el primero en estudiar y documentar el mapudungu(n), la lengua originaria principal que se habla en lo que hoy es Chile, desde un marco científico y etnolingüístico (Sánchez 1992). A través de estos empeños, llegó a la conclusión personal de que el mapudungun había influido de manera considerable en el castellano chileno, poniendo de relieve el inventario fonético chileno y aseverando que el mismo consistía extensivamente en sonidos del mapudungun (Lenz 
1940). Tales aseveraciones lograron engendrar un febril debate que no ha logrado resolverse de forma universalmente satisfactoria hasta el día de hoy.

Los que se opusieron a la teoría de Lenz (1940), tales como Alonso (1953) y Oroz (1966), han insistido que los rasgos que Lenz atribuye a la influencia del mapudungun son meramente consecuencias naturales de la misma lengua española y sus respectivos subsistemas lingüísticos. Sin embargo, pese a su firme oposición a las aseveraciones de Lenz, tanto Alonso como Oroz, no negaron ni se opusieron a la posibilidad de que el mapudungun influenciara en la fonología prosódica chilena, centrándose específicamente en la entonación. Afirma Oroz “...nuestra entonación difiere bastante de la española, y a juicio nuestro, es lo más probable que las entonaciones regionales tengan un origen indígena; además, es un hecho bien conocido que el que adopta una nueva lengua, conserve, en general, la entonación de la que habló primitivamente." (p.190). Lamentablemente, Lenz hizo escasa mención de la entonación en sus estudios del castellano chileno y el mapudungun, y nunca exploró la posibilidad de que el mapudungun dejase una huella en la fonología entonacional del español hablado en Chile.

Dado todo lo anterior, el presente trabajo pretende explorar más a fondo la cuestión de la influencia del mapudungun en la entonación del español chileno. En específico, se centra en el comportamiento prosódico de unos patrones entonativos del mapudungun y el español chileno conocidos como "mesetas" entonacionales (Rogers 2013, 2016). Se analiza dicho comportamiento desde los puntos de vista de la fonética, la sintaxis, la pragmática y la prosodia. Se demuestra que varias de las similitudes observadas en las mesetas de ambas lenguas pueden considerarse evidencia a favor de la posibilidad de que el papel discursivo que desempeñan fuese adoptado al español chileno del mapudungun.

\section{LITERATURA}

\subsection{LAS Mesetas ENTONACIONALES EN EL ESPAÑol DE CHILE}

Dado que esta investigación tiene como objetivo principal el análisis de una especie específica de meseta entonacional, profundizar en la fonología entonativa general del español chileno no cabe dentro de los parámetros actuales. La entonación del español chileno se ha detallado en varios estudios anteriores (véase Silva-Corvalán 1983, Cepeda 1997, Cid y Ortiz 1998, Ortiz, Fuentes y Astruc 2010, Fuentes 2012 entre varios más). En el español chileno se ha informado de algunos tipos de contornos tipo meseta 
en una variedad de contextos pragmáticos. Cid y Ortiz (1998) hacen breve mención de una meseta que observaron como uno de varios contornos que documentaron en contextos vocativos del habla santiaguina. Más tarde, a base de datos de habla más controlada, Ortiz et al. (2010) informaron de mesetas entonacionales producidas en contexto interrogativo absoluto.

Aunque bastante parecidas en su forma fonética a las mesetas interrogativas ya mencionadas, las que se analizan en la presente investigación no se observan en dicho entorno pragmático. Rogers $(2013,2016)$ indica que éstas empiezan con un valle entonacional en el que todo el contenido fonético se mantiene en el mismo registro tonal. Este valle no está siempre presente, pero se manifiesta con una frecuencia de notabilidad. Esta porción puede extenderse de unas pocas sílabas hasta numerosas palabras, tanto las que típicamente llevan acento prosódico como las que no lo suelen llevar. La porción de la meseta inicia con un acenso tonal abrupto a un registro tonal alto. Si hay un valle, el acenso comienza en la última sílaba acentuada de la última palabra del valle. Esta subida tonal puede solo ocurrir por lo que dure la palabra en la que inicia o puede seguir su trayectoria ascendente durante varias sílabas o palabras más. Al lograr el registro tonal deseado, los hablantes mantienen una variedad de contenido léxico en este nivel tonal alto. Esta porción del contorno es por lo que más se destacan estos patrones, ya que puede extenderse durante unas pocas sílabas o puede lograr contener un número considerable de palabras acentuadas y no acentuadas. La última porción del contorno es un descenso tonal que, en la gran mayoría de las observaciones de los estudios anteriores, empieza en la última sílaba acentuada de la porción alta y concluye al término de la misma palabra en la que inicia. En algunos casos el descenso comienza en la última sílaba de la porción, lleve o no acento prosódico; y en otros casos, comienza en la última sílaba acentuada y desciende durante varias sílabas y/o palabras.

Una minoría de observaciones demuestra que hay ciertas producciones en las que los contornos carecen de un descenso final y otras cuyo descenso ocurre después de un ascenso tonal en la última sílaba acentuada. Debe notarse también que algunas mesetas inician al principio de un enunciado y se extienden hasta el final del mismo. Rogers $(2013,2016)$ nota que la duración de las mesetas y la cantidad de contenido que contengan parece depender en gran medida de los deseos comunicativos de los mismos locutores y en menor grado de otros factores puramente lingüísticos. Es decir que hasta cierto grado el locutor parece estar consciente de que produce una meseta entonacional por lo que este mismo determina el tamaño de la meseta dentro del enunciado completo. Las figuras 1 y 2 , respectivamente, son ejemplos de una meseta entonacional corta y una más larga producidas por locutores nativos del castellano chileno. 


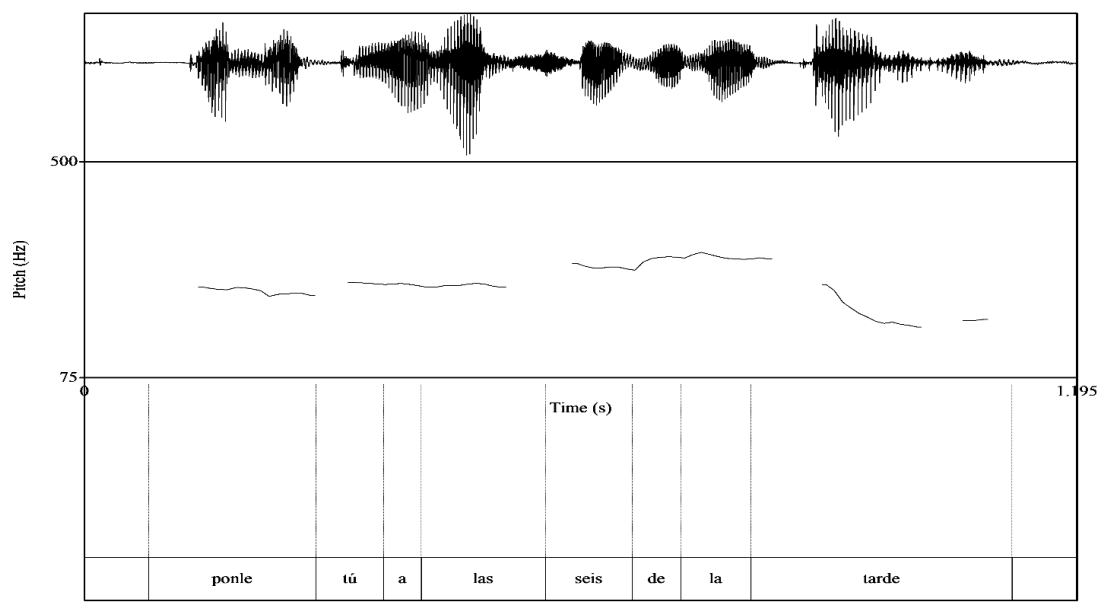

Figura 1: Meseta corta del castellano “...ponle tú a las seis de la tarde...”

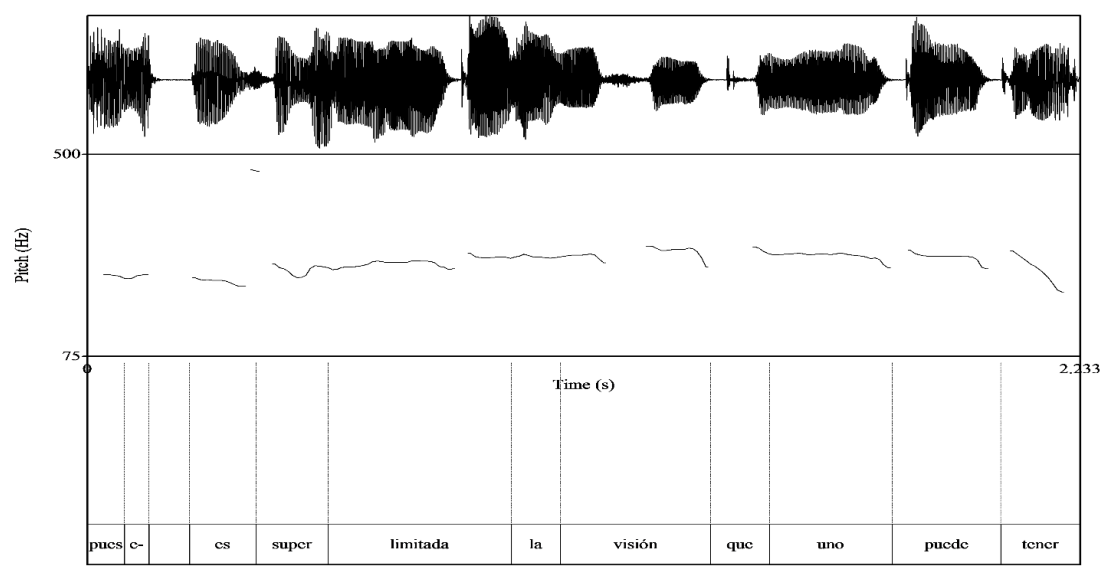

Figura 2: Meseta larga del castellano "pues e- es super limitada la visión que uno puede tener..." 


\subsection{LAS MESETAS ENTONACIONALES EN OTRAS LENGUAS Y VARIEDADES DEL ESPAÑOL}

Debe notarse que la existencia de mesetas entonacionales no es rasgo único de la fonología entonativa chilena. Se han estudiado estos contornos y otros parecidos en una variedad de otras lenguas de tipología diversa y en unos cuantos dialectos de la lengua española. Sin embargo, los contextos pragmáticos en los que se producen y lo que los locutores pretenden comunicar no son iguales aun entre dialectos de la misma lengua española. Por consiguiente, el aporte pragmático y fonológico de la forma fonética de una meseta entonacional no son universales y dependen estrechamente de la comunidad lingüística en la que se empleen. Interlingüísticamente, se ha documentado la producción de mesetas entonacionales en el inglés (Ladd 2008), guaraní (Clopper y Tonhauser 2011), k'iche' (Yasavull 2013), vasco (Elordieta 2003) y el alemán tirolés (Féry 1993, Barker 2005).

En el español, estos contornos han aparecido mayormente en diferentes contextos interrogativos. Se emplean en contexto interrogativo absoluto en el español hablado en Puerto Rico (Armstrong 2010), la República Dominicana (Willis 2010) y los Andes venezolanos (Astruc, Mora y Rew 2010). En el castellano de las Canarias (Cabrera y Vizcaíno 2010) y el de Galicia como segunda lengua de hablantes nativos del gallego (Pérez 2015), en ocasiones se observan mesetas que comunican preguntas informativas. El español porteño presenta mesetas entonacionales en contextos declarativos (Gabriel, Feldhausen \& Pešková 2011), pero debe advertirse que las mesetas porteñas son de tamaño y duración mucho menores que las que se observan en los otros dialectos ya mencionados. Si bien es cierto que la mayoría de las mesetas que se producen en estos dialectos tienen muchos parecidos fonéticos con las del castellano chileno, más allá de lo fonético y el contexto pragmático en el que aparecen, no se sabe mucho más respecto a su comportamiento lingüístico.

\subsection{EL MAPUDUNGUN}

El mapudungun es una lengua tipológicamente distinta al español y las demás lenguas originarias que se hablan en el Cono Sur. Su origen es desconocido, ya que existe una carencia casi total de evidencia genética definitiva del mapudungun (Smeets 2008) por lo que sigue siendo tema de debate entre lingüistas. Según Adelaar (2004), es posible que esto sea la consecuencia de la rápida extinción y ausencia de documentación de una gran cantidad de lenguas andinas durante los últimos cinco siglos. Él asevera que la pérdida 
y falta de documentación de tantas lenguas originarias de la región andina "implican la pérdida de una cantidad de vínculos equivalente a las lenguas que aún existen" (p.22, traducción propia).

No se sabe con exactitud cuántos hablantes del mapudungun viven en Chile en la actualidad. Según Zúñiga (2007), las estimaciones más conservadoras indican que esa cifra alcanza los 200.000 hablantes y que los que lo hablan con mayor fluidez son los individuos de edad más avanzada que residen en las zonas rurales. Según el censo chileno del año 2002, más del $87 \%$ de los individuos que se identificaron con una etnia, indicaron que tenían algún grado de ascendencia mapuche (Comisión nacional del XVII Censo de la Población y VI de Vivienda 2002).

El mapudungun y el castellano no han logrado existir en armonía y como consecuencia el primero ha sufrido una gran medida de marginalización y estigmatización. Salas (2001) asevera que, de las dos lenguas, el castellano "es la que impone, sin concesión alguna, las reglas de interacción, entre otras, la de hablar castellano." (p. 44). La Organización de Naciones y Pueblos sin Representación (The Unrepresented Nations and Peoples Organization) indica que, para el pueblo mapuche, la lengua y la cultura van de la mano y que, debido a la discriminación, los hablantes más jóvenes no siempre aprenden a hablar mapudungun y, en algunos casos, dejan de identificarse como mapuches. Salas (2001) también afirma que muchos padres mapuches consideran que sus hijos tendrán mayores oportunidades si hablan castellano a costa del mapudungun.

La mayoría de los estudios del mapudungun que hay son de índole descriptiva y gramatical. Smeets (2008) indica que la morfología de los verbos del mapudungun es bastante compleja y que la lengua cuenta con un orden de palabras altamente libre y flexible. Es una lengua aglutinante y polisintética, lo cual quiere decir que forma palabras complejas mediante la combinación de partículas, o morfemas, que indican conceptos como tiempo, pluralidad, modo, voz, inclusividad, posesión, instrumentalidad, etc. Por ejemplo, Smeets (2008, p. 17) afirma que, en el mapudungun, un verbo consiste en una raíz verbal, la cual va seguida de por lo menos un sufijo derivacional y otro infleccional. El ejemplo 1, tomado de Smeets (2008), y el ejemplo 2, propio del autor, demuestran la composición de un verbo en el mapudungun.

1) $а т и-y \quad-m \quad-i$ IR -INDICATIVO- $2^{\mathrm{a}}$ PERSONA -SINGULAR "fuiste" 


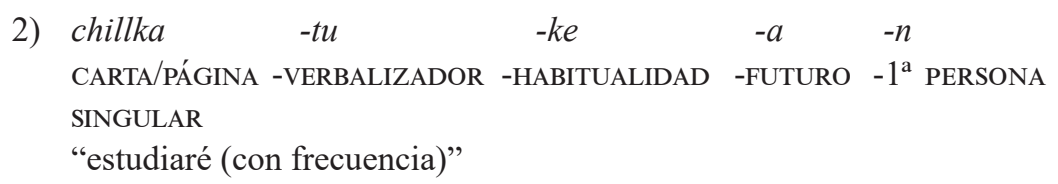

Pocos estudios sobre la fonología prosódica del mapudungun se han realizado, y los que existen apenas proporcionan un vistazo mayormente descriptivo de una cantidad limitada de asuntos prosódicos de esta lengua como, por ejemplo, el acento prosódico. El acento prosódico no se emplea para comunicar significado léxico en el mapudungun, al igual que en muchas lenguas como el castellano y el inglés. A diferencia del castellano, la colocación del acento prosódico puede ser mucho más fluida y flexible sin que ocurra ningún cambio de significado (Zúñiga 2007). Por ejemplo, la palabra kofke (pan) puede decirse ['kof.ke] tanto como [kof.'ke] y su aporte léxico no cambia. Sin embargo, existen ciertos parámetros que gobiernan la acentuación, y en algunos casos, la presencia del acento prosódico puede cambiar el significado pragmático de un enunciado o de una palabra. Por ejemplo, la acentuación de la primera sílaba de la palabra chádi (sal) indica que ésta ocurre en contexto declarativo, mientras que acentuar la última sílaba es señal de un contexto interrogativo, tal como se ilustra en el ejemplo 3 de Zúñiga (2007).

3) Ngillamean chádi fewla. (Iré a comprar sal ahora.)

Ngelay chadi tachi ruka mew? (¿No hay sale en la casa?)

Lo que más se ha dicho sobre la prosodia y la entonación del mapudungun entre lingüistas es que es muy probable que sea el subsistema lingüístico que más impacto ha tenido en el castellano chileno (Alonso 1953, Oroz 1966), aunque esta idea no se ha respaldado con ningún estudio formal. Croese (1985) señala que existen algunas diferencias rítmicas y entonativas entre diferentes dialectos del mapudungun que pueden resultar en dificultades de inteligibilidad interdialectal. Oroz (1966) postula que, en ocasiones, el castellano chileno se distingue de forma tan notable en su entonación de otros dialectos del español precisamente por la influencia del mapudungun, pero no proporciona muchos detalles al respecto. Sin embargo, parece insinuar que el tono más melódico de "canto" por el que algunas regiones del país se caracterizan, se arraiga en el mapudungun. Hasta la fecha, no existe ningún estudio que describa la fonología entonacional del mapudungun. 


\subsection{El CONTACTO CUlTURAL ENTRE LOS MAPUCHE Y EL PUEBLO CHILENO}

El pueblo mapuche siempre se ha resistido a las fuerzas ocupantes y su relación con el Estado chileno ha sido mayormente contenciosa, en especial a partir de la dictadura militar, durante la cual el pueblo mapuche sufrió un mayor grado de opresión (Smeets 2008). Estas tensiones entre los mapuche y el gobierno chileno han hecho más difícil la tarea de llevar a cabo estudios lingüísticos que documenten los efectos del contacto entre el mapudungun y el castellano chileno. Sin embargo, existe evidencia biológica que señala el contacto cultural entre los dos grupos, la cual permite, hasta cierto punto, la deducción respecto al posible nivel de contacto lingüístico ocurrido entre las dos lenguas.

Además de los más de 600.000 chilenos que confirmaron en el censo del 2002 tener cierto grado de ascendencia mapuche, un par de estudios informa sobre niveles notables de mezcla genética amerindia en individuos principalmente santiaguinos. Cruz-Coke y Moreno (1994) analizó el ADN nuclear, el cual contiene componentes de ambos progenitores, de las ciudades norteñas de Santiago y Valparaíso. Los hallazgos de sus análisis demuestran niveles elevados de mezcla amerindia que se hacen cada vez mayores en los individuos de clases económicamente menos privilegiadas en ambas ciudades. En una investigación posterior, Rocco et al. (2002) analizó el ADN mitocondrial, el cual solo contiene componentes genéticos maternos, y concluyeron que el $84 \%$ de la población santiaguina tiene ADN materno de origen amerindio. Cabe mencionar que el término "amerindio" debe interpretarse como para incluir los grupos aimara y atacameño con el mapuche, dado que ambos estudios se realizaron en el norte del país. Sin embargo, el pueblo mapuche supera en número a todos los demás pueblos originarios en Chile, especialmente en las zonas más al sur. Aunque no son de naturaleza lingüística, lo que indican estos análisis genéticos es que históricamente hubo períodos relativamente intensos de contacto cultural y social entre el pueblo chileno y la gente mapuche.

Ante esta posibilidad, resulta poco probable que hubiera tanto intercambio social y cultural sin que las lenguas de las dos comunidades se influenciaran a cierto grado. Sin embargo, Salas (2001) asevera que el castellano ha tenido mayor impacto en el mapudungun que la inversa, uniéndose a lo que dijeron lingüistas anteriores a él como Alonso (1953) y Oroz (1966). Según estos autores, esto indica que el castellano ha logrado alterar algunos aspectos de unos cuantos subsistemas lingüísticos más profundos del mapudungun, mientras que el mapudungun solo ha contribuido al léxico y los nombres topónimos del castellano. 
Pese a esas aseveraciones, un par de investigaciones más recientes ha evidenciado la posibilidad de que el mapudungun tuviese un impacto más profundo en el castellano de los chilenos. Sadowsky (2013 y este volumen) realizó un análisis de las vocales del español de la ciudad de Concepción y las del mapudungun hablado en la isla Huapi. Los datos que presenta demuestran que las distribuciones vocálicas de ambas lenguas son bastante parecidas, por lo que postula que debido al contacto con el mapudungun, existe la posibilidad de que las vocales chilenas sufrieran una refonetización. Posteriormente, Sadowsky y Aninao (2013) investigaron la inconcordancia de número como rasgo nativo en una variedad del castellano hablado en el sur de Chile. Los autores afirman que mientras la concordancia de número es obligatoria en el castellano, es optativa en muchos casos en el mapudungun. Demuestran que la inconcordancia de número existe como rasgo nativo entre los hablantes monolingües del español en la población que analizaron. Arguyen que sus datos muestran que, en esa población, el mapudungun logró influir en la morfosintaxis del castellano. Las conclusiones de ambos estudios son significativas porque tradicionalmente la fonología y la morfosintaxis se han considerado desmesuradamente resistentes al cambio en situaciones de contacto lingüístico (p. ej. Thomason y Kaufman 1988, Silva Corvalán 1994, Van Coetsem 2000).

\subsection{LA ENTONACIÓN Y EL CONTACTO LINGÜÍSTICO}

A diferencia de los subsistemas más profundos como la fonología, la sintaxis y la morfosintaxis, se ha establecido que la entonación es más moldeable y vulnerable a las influencias de otras lenguas. Por ejemplo, Simonet (2011) concluye que, dentro del plazo de solamente unos pocos años, ciertos españoles que vivían en la isla de Majorca presentaron rasgos catalanes en las porciones nucleares de algunas declarativas de foco amplio. Además, este estudio demuestra que los españoles que más interés tenían en integrarse a la cultura de Majorca tendían a adoptar esos rasgos de su segunda lengua con más prontitud. Respecto al español cubano de Miami, Alvord (2010) informa que, en contexto interrogativo absoluto, los hablantes con más contacto con el inglés y otros dialectos del español son más propensos a terminar una interrogativa absoluta en un acenso tonal en lugar del descenso por el que típicamente se caracterizan las interrogativas absolutas cubanas. Otras investigaciones como O'Rourke (2005), Romera y Elordieta (2013), Hualde y Schwegler (2008) y Colantoni (2011) señalan que una multiplicidad de variables, tales como tiempo de contacto, frecuencia de exposición a otra lengua, percepción sociolingüística y grado de integración social pueden 
correlacionarse con el grado al cual la entonación de una lengua se ve afectada por la de otra.

\subsection{EL PRESENTE ESTUDIO}

Si el mapudungun logró influenciar la fonología vocálica y la morfosintaxis del castellano chileno, tal como lo sugieren Sadowsky (2013) y Sadowsky y Aninao (2013), entonces, dada la vulnerabilidad de la entonación al cambio ante el contacto de lenguas, amerita investigar la posibilidad de que existan huellas del mapudungun en la entonación del español chileno. La presente investigación pretende realizar un análisis taxativo de la influencia del mapudungun en las mesetas entonacionales del español chileno ya descritas. Además, procura abrir camino para la futura investigación de la prosodia del mapudungun como factor influyente más amplio en el español hablado en Chile. Las siguientes preguntas de investigación sirvieron de base para el estudio:

1) Según la evidencia existente ¿qué papel comunicativo pueden desempeñar las mesetas entonacionales en las dos lenguas? ¿Se debe su uso al contacto lingüístico con el mapudungun?

2) ¿Cuáles son las implicaciones para la teoría araucanista de Lenz?

\section{MÉTODOS}

Actualmente la recolección de datos en mapudungun es una tarea difícil debido a la relación tumultuosa que tiene la comunidad mapuche con el Estado chileno. Por lo tanto, fue necesario acudir a las siguientes fuentes de acceso abierto para obtener los datos del mapudungun para el estudio: Zúñiga (2007), Smeets (2008) y Olate (2015). Zúñiga (2007) consiste en grabaciones de enunciados y conversaciones cortos para su libro de gramática y Smeets (2008) se compone de entrevistas sociolingüísticas y cuentos cortos de tres individuos mapuches que se refugiaron en Holanda durante la dictadura militar de Augusto Pinochet. Los datos de Olate (2015) forman una colección personal de entrevistas informales y conversaciones controladas con individuos mapuches a la que el Dr. Aldo Olate de la Universidad de la Frontera en la ciudad de Temuco me permitió acceder. Todos los datos fueron analizados como archivos tipo .wav y sometidos al análisis acústico con el programa de software Praat (Boersma y Weenink 2015). 
Los datos del español chileno provienen de 50 entrevistas sociolingüísticas grabadas en las regiones del Biobío y La Araucanía de Chile. De las 50 entrevistas, 44 fueron realizadas en las ciudades de Concepción y Talcahuano y las poblaciones circuncidantes de Villa San Pedro, Michaihue, Boca Sur, Candelaria, Hualpén y Lomas Coloradas. Las seis restantes fueron hechas en la Universidad de la Frontera (UFRO) en Temuco. Estas últimas fueron grabadas con una grabadora digital Fostex FR-2LE con un micrófono Audix HT5 colocado en la cabeza y se llevaron a cabo en un cuarto apartado y silencioso en la UFRO con cuatro individuos temuquenses y dos santiaguinos que estudiaban en esta universidad. La mayoría de las entrevistas de Concepción y Talcahuano fueron realizadas en los hogares respectivos de los mismos participantes. Unas cuantas más se grabaron en oficinas e iglesias locales. Todas fueron grabadas o con el mismo tipo de equipo empleado en Temuco o con una grabadora digital Marantz PMD660. Las entrevistas duraron de 12 minutos a más de 30 minutos. De los 50 participantes, 26 eran mujeres y 24 eran hombres, provenientes de una variedad de estratos sociales y de entre 18 y 55 años de edad. Al igual que los datos de mapudungun, todos los datos fueron analizados como archivos tipo .wav y sometidos al análisis acústico con el programa de software Praat (Boersma y Weenink 2015).

\section{RESULTADOS}

En total, se extrajeron 530 mesetas de los datos de castellano y 34 de los de mapudungun. Las mesetas entonacionales que fueron extraídas de los datos de ambas lenguas fueron analizadas a base de los siguientes criterios: la forma fonética, la variabilidad duracional de la extensión de la porción alta, el comportamiento prosódico y sintáctico del acenso inicial y el contexto pragmático en que ocurrieron. A continuación, se proporcionan ejemplos específicos de estos criterios observados en los datos, ya que son tantos los casos que resulta imposible incluir toda instancia de cada criterio en esta sección.

\subsection{FORMA FONÉTICA}

A primera vista, las mesetas observadas en las dos lenguas presentan formas fonéticas bastante parecidas. Aunque este tipo de observación parezca algo 
superficial, es importante confirmar que se manifiesta de manera similar al nivel fonético para que sea posible verificar que algún tipo de transferencia fonológica o pragmática ha tenido lugar. A continuación, la figura 3 presenta una meseta que fue observada en los datos castellanos y la figura 4 muestra una meseta del mapudungun del cuerpo de datos de Smeets (2008).

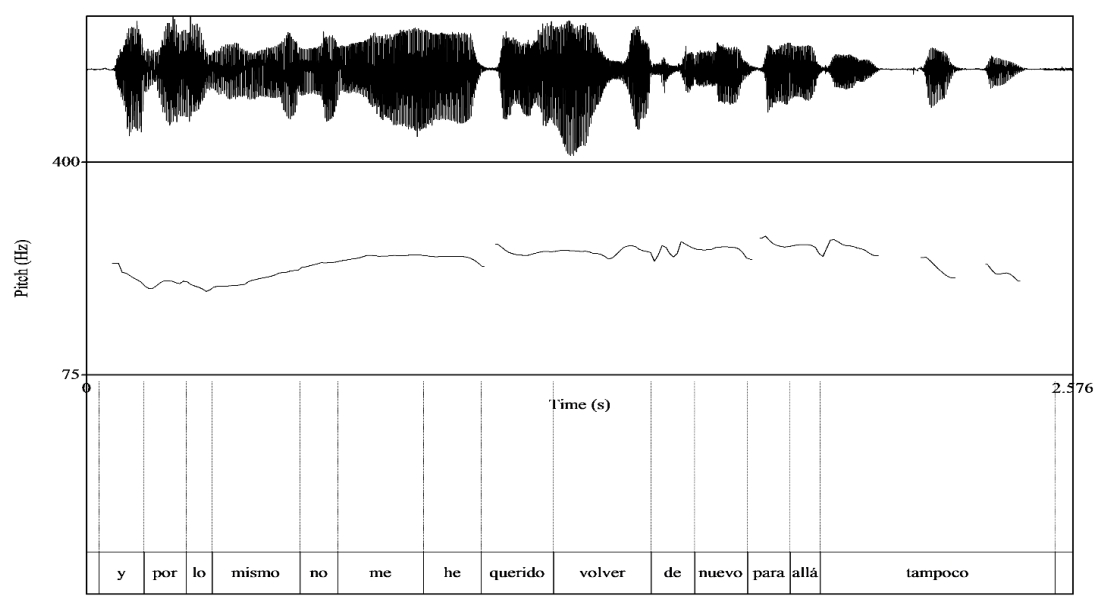

Figura 3: Meseta castellana “...y por lo mismo no me he querido volver de nuevo para allá tampoco.”

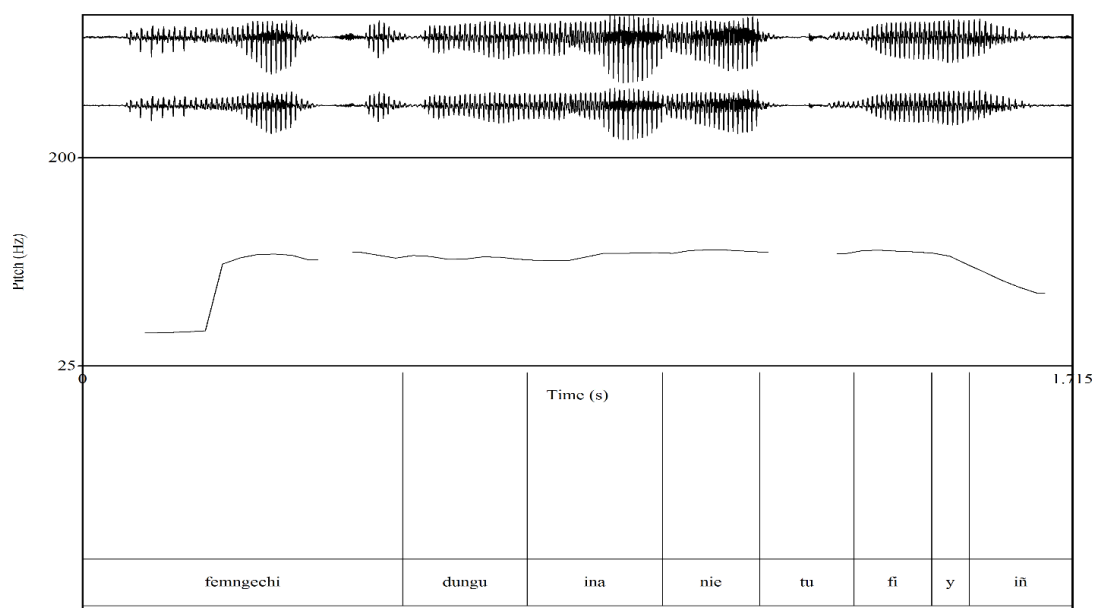

Figura 4: Una meseta del mapudungun “...femngechi dungu inanietufiyiñ...” (“... así nos adherimos a esta idea...”) 
Como se aprecia en ambos ejemplos, los dos contornos comienzan con asensos tonales relativamente abruptos, aunque el del ejemplo del castellano parece ser más gradual ya que se extiende a través de tres palabras (...mismo no me). El del mapudungun parece iniciar poco después de la primera sílaba de la palabra femngechi. En las porciones altas de los dos contornos entonativos, los locutores respectivos mantienen el mismo registro tonal alto durante una variedad de contenido. En el ejemplo del español, la porción alta consiste en 7 palabras, o 12 sílabas, antes del descenso final que se da en la sílaba tónica de la última palabra tampoco. Puesto que el mapudungun es aglutinante, todo el enunciado se compone de solamente tres palabras, pero la porción alta se compone de 9 sílabas y cierra en la última -yiñ.

Además de tener formas fonéticas similares, en ambas lenguas, las mesetas presentaron comportamientos distintos que ocurrieron principalmente en lo que es la última porción de los contornos -desde el inicio del descenso final hasta el cierre. Estas alternativas fonéticas se apreciaron con tanta consistencia que fue posible dividir los contornos de ambas lenguas en subcategorías distintas, aunque sin datos perceptuales es imposible saber si esas diferencias son meramente representaciones alofónicas de una sola forma subyacente o si tienen alguna función fonológica más profunda. En las dos lenguas, la mayoría de los descensos iniciaban en la última sílaba tónica del contorno (véanse las figuras 3 y 4 ). Estas mesetas se categorizaron como "tipo 1". Como se explicó anteriormente, se observó que algunas mesetas tenían descensos más alargados que comenzaban en una sílaba tónica, pero que persistían durante varias sílabas y/o palabras más. Estos contornos pertenecen a la llamada categoría "tipo 2". Las figuras 5 y 6 son ejemplos de unas mesetas tipo 2 del castellano y el mapudungun, respectivamente. Por último, las dos lenguas cuentan con mesetas que, en lugar de terminar en un descenso final que inicia en la última sílaba tónica, ascienden a un registro tonal aún más alto que el del contenido de la porción alta. Este movimiento tonal ascendente comienza y culmina dentro de la misma sílaba. Luego, la frecuencia fundamental baja en todo el contenido restante. Estas mesetas figuran en la categoría de "tipo 3". 


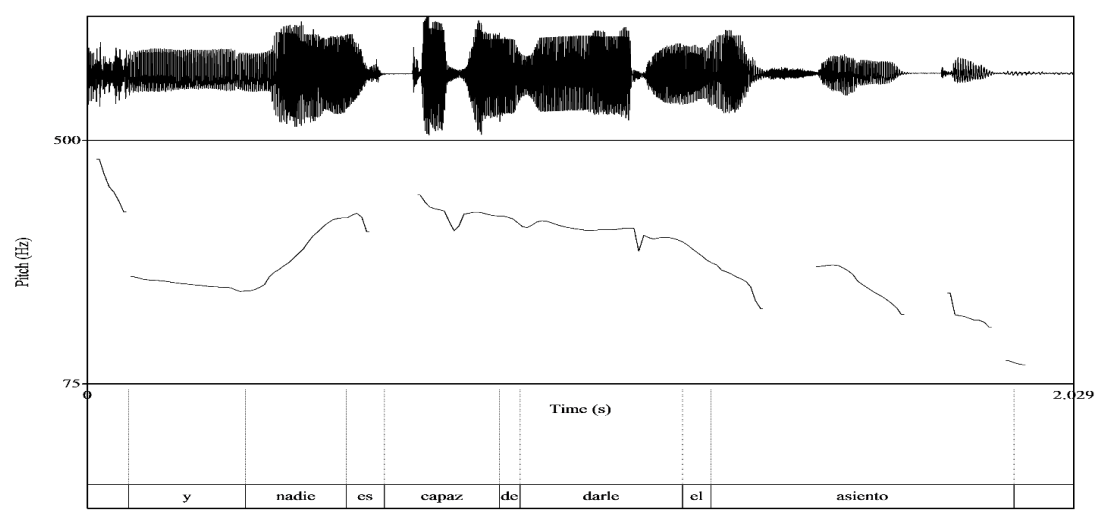

Figura 5: Meseta tipo 2 del castellano “...y nadie es capaz de darle el asiento...”

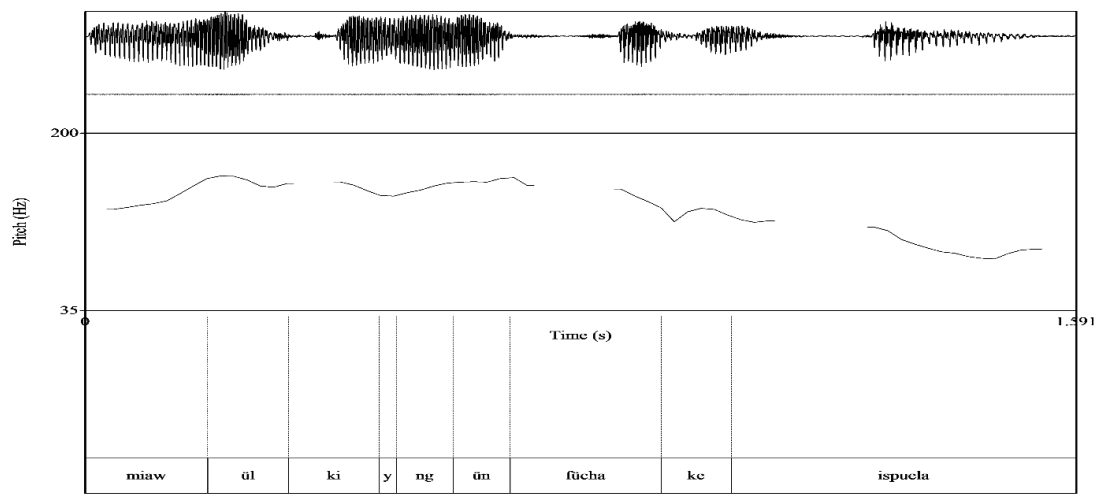

Figura 6: Meseta tipo 2 del mapudungun “...miawülkiyngün füchake ispuela...” (“...ambulan con grandes espuelas...”)

En la figura 5 se observa que tras mantenerse la porción alta en las palabras es, capaz y de, el declive de la frecuencia fundamental se realiza en las últimas tres palabras, o 6 sílabas, del enunciado. En la figura 6, extraída de Smeets (2008), se aprecia un comportamiento semejante al de la meseta castellana de la figura anterior. El locutor mantiene la porción alta en 4 sílabas e inicia la bajada en la penúltima sílaba de füchake, y la frecuencia fundamental disminuye durante las últimas cuatro sílabas del enunciado. Las figuras 7 y 8 proporcionan ejemplos de mesetas tipo 3 del castellano y el mapudungun, respectivamente. 


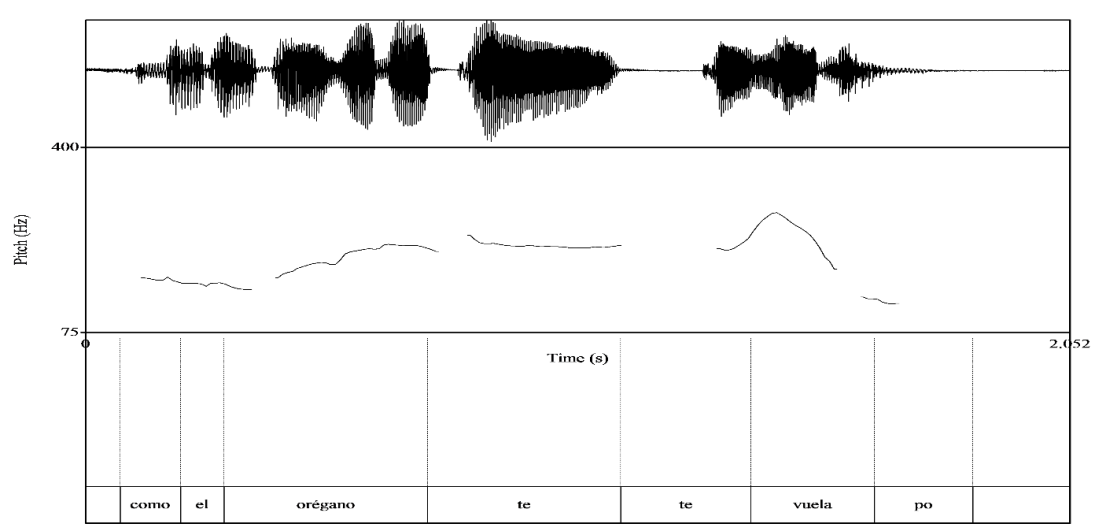

Figura 7: Meseta tipo 3 del castellano “...como el orégano te, te vuela po...”

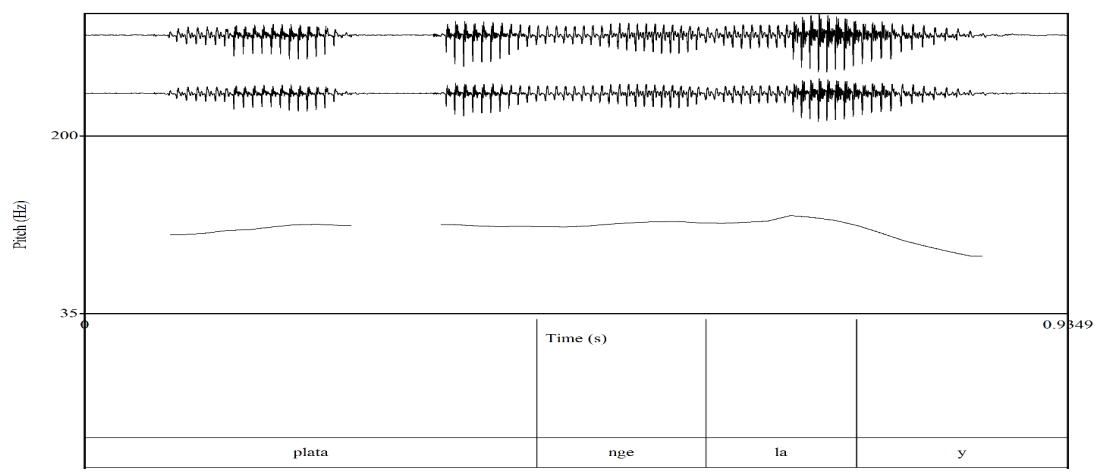

Figura 8: Meseta tipo 3 del mapudungun “...plata ngelay...” (“...no hay plata...”)

En la figura 7, el locutor mantiene la porción alta durante 3 sílabas hasta llegar a la última palabra acentuada, vuela, del enunciado. En esta palabra, asciende en la sílaba tónica a un registro tonal que supera el del resto del contenido de la porción alta. Después, baja rápidamente en las últimas dos sílabas del enunciado. La figura 8 de Smeets (2008) también presenta una subida tonal en la última parte de la porción alta de la meseta. En este caso, el locutor alcanza un registro tonal más alto en el morfema la, el cual indica negación en el mapudungun. La frecuencia fundamental llega a una cumbre dentro de la misma sílaba en la que asciende, y baja en el último morfema $y$. 


\subsection{VARIABILIDAD DURACIONAL DE LA EXTENSIÓN DE LA PORCIÓN ALTA}

Una de las características más notables de las mesetas entonacionales tanto en el castellano como en el mapudungun, es la gran variabilidad de tamaño que presentan en sus respectivas porciones altas. Es decir, los locutores demuestran la tendencia de reducir o aumentar la duración y la cantidad de contenido que figura en la porción alta de modo que ésta pueda componerse de unas cuantas sílabas o una gran cantidad de palabras. En las figuras 9, 10 y 11 se aprecian mesetas cuyas porciones altas contienen poco contenido.

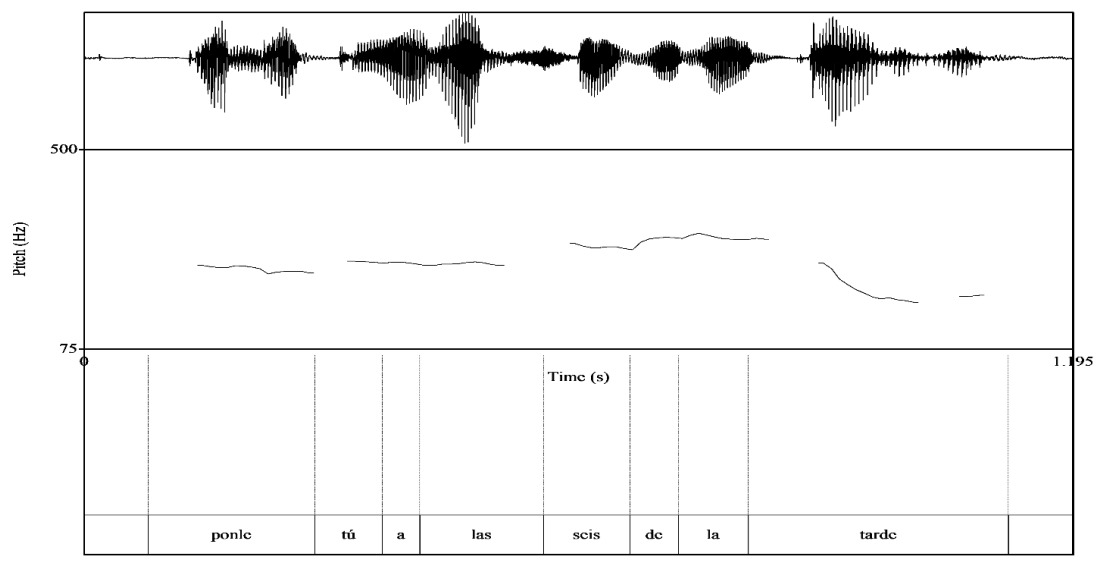

Figura 9: Meseta del castellano con poco contenido en la porción alta “(...ponle tú, a las seis de la tarde...”)

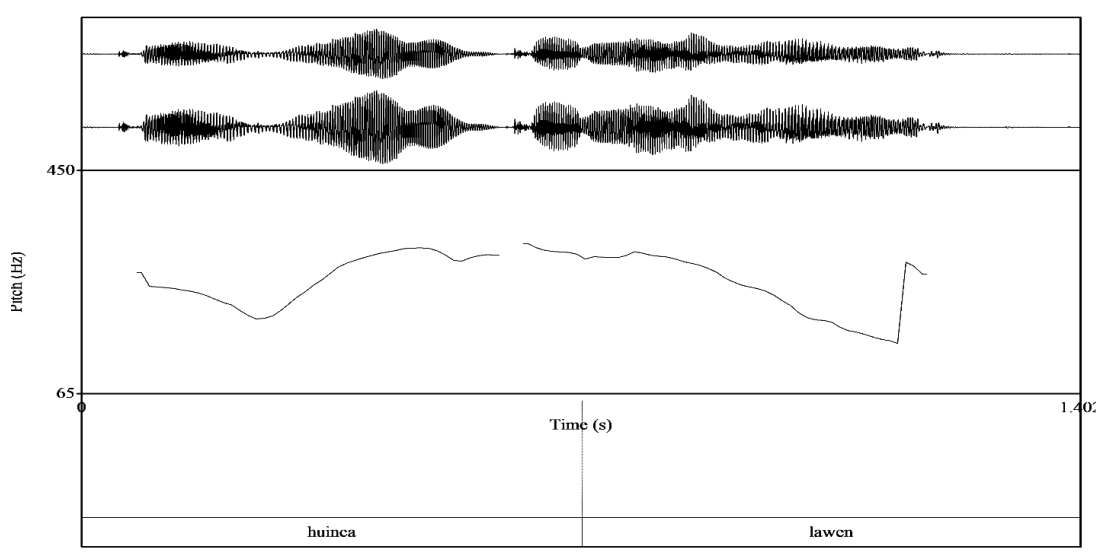

Figura 10: Meseta del mapudungun cuya porción alta consiste en poco contenido “...huinca lawen..." (“...remedio huinca...”) 


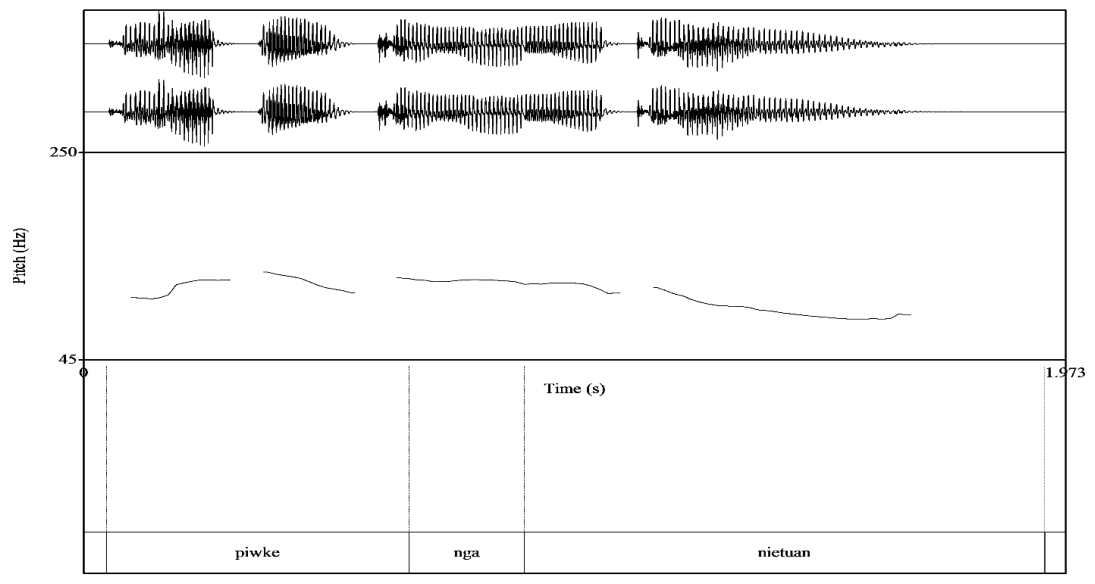

Figura 11: Meseta del mapudungun con una porción alta corta “... piwke nga nietuan...” (“...tendré [tres] corazones...”)

La porción alta de la meseta del castellano en la figura 9 consiste en dos sílabas al igual que ambas porciones altas de las mesetas del mapudungun en las figuras 10 (Olate 2015) y 11 (Zúñiga 2007). A continuación, las figuras 12 y 13 (Smeets 2008) proporcionan mesetas entonacionales de ambas lenguas cuyas porciones se mantienen durante una cantidad notablemente mayor de contenido. El contorno de la figura 12 cuenta con una sección alta que la locutora mantiene en 7 palabras, o 20 sílabas, mientras que en la figura 14, el locutor del mapudungun produce un total de 13 sílabas en la porción alta.

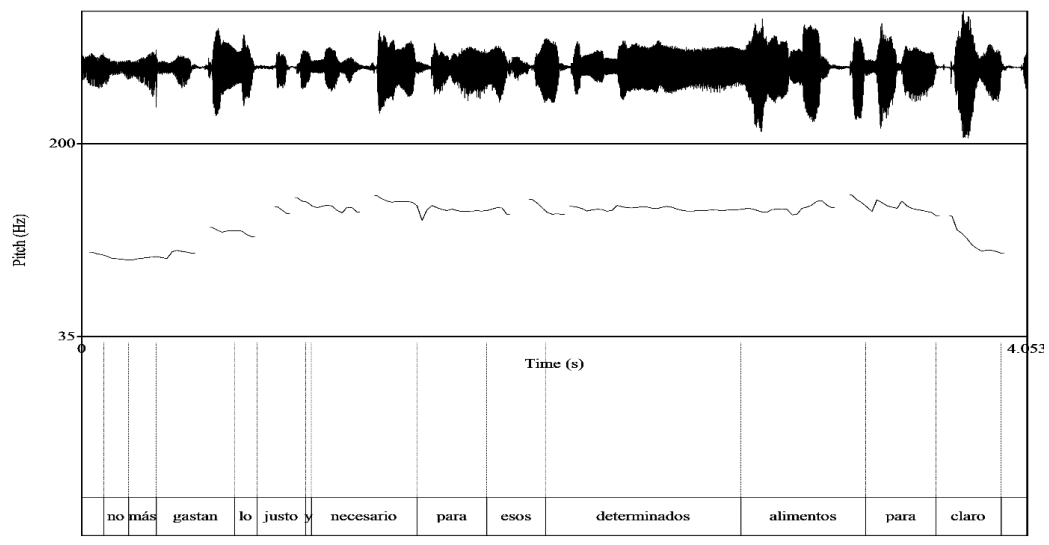

Figura 12: Meseta del castellano con una gran cantidad de contenido en su porción alta “...no más gastan lo justo y necesario para esos determinados alimentos para, claro..." 


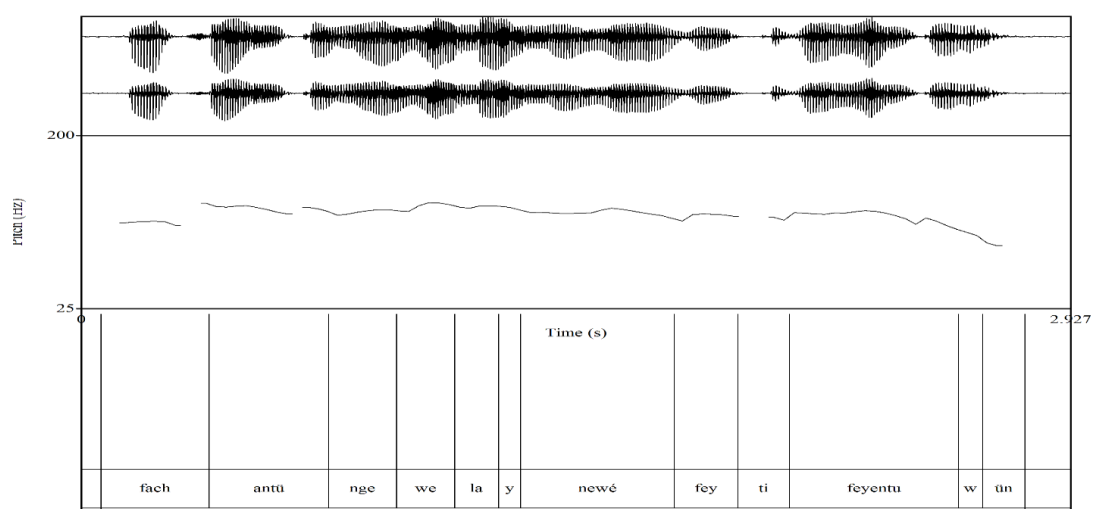

Figura 13: Meseta del mapudungun con una gran cantidad de contenido en su porción alta “...fachantü ngewelay newe feyti feyentuwün...” (“...ya no hay tanta confianza...”)

\subsection{EL COMPORTAMIENTO PROSÓDICO Y SINTÁCTICO DEL ASCENSO INICIAL}

De acuerdo con las aseveraciones hechas en estudios anteriores sobre la relación entre el acento prosódico español y la frecuencia fundamental (p. ej. Face 2003, Rao 2009), cuando un locutor aumenta la frecuencia fundamental, lo hace mayormente en sílabas acentuadas con el fin de destacar ciertos elementos léxicos del resto del contenido. Los datos de la presente investigación presentan casos en los que ciertos locutores de ambas lenguas iniciaron algunos ascensos iniciales en contenido que tradicionalmente se ha considerado carente de acento prosódico, tales como ciertos numerales, pronombres de objeto y artículos (Quilis 1999). Subsiguientemente, se observan una meseta del mapudungun (Smeets 2008) en la figura 15 y una de castellano en la figura 16 cuyas porciones iniciales empiezan a ascender en numerales. 


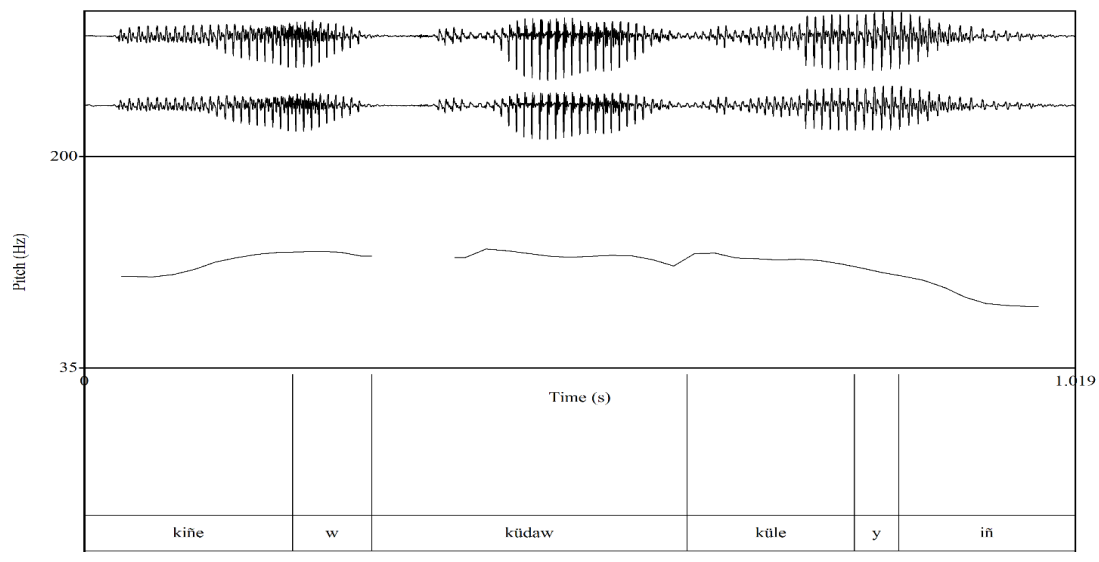

Figura 14: Meseta del mapudungun que empieza en un numeral “... kiñew küdawküleyiñ...” (“...trabajamos juntos/unidos...”)

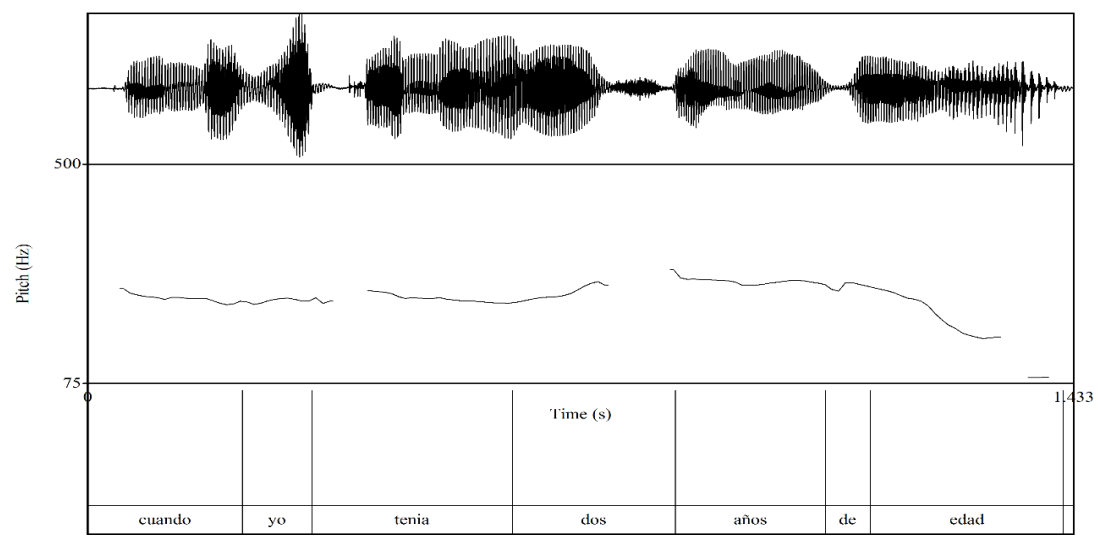

Figura 15: Meseta del castellano cuyo ascenso inicial comienza en un numeral "...cuando yo tenía dos años de edad..."

En el ejemplo del mapudungun, la frecuencia fundamental aumenta en la palabra kiñe, la cual de manera subyacente es un numeral. Sin embargo, debe notarse que en este caso, debido a la naturaleza aglutinante del mapudungun, podría argüirse que figura como parte del verbo, dando lugar a kiñewküdawküleyiñ, por lo que no funciona como numeral tradicional. Sin embargo, en este caso, (Smeets 2008) lo trata como numeral independiente del verbo küdawküleyiñ, agregándole el morefema $-w$ que expresa reflexividad. En el ejemplo del castellano, la meseta inicia en el numeral 
dos. Teóricamente, en el castellano los numerales pueden producirse sin acentuación (Quilis 1999), aunque esta noción continúa en debate. Cabe señalar que los estudios respecto al acento prosódico en el mapudungun son relativamente escasos, por lo que no se puede afirmar que su uso y distribución son iguales a los del castellano. De hecho, al parecer, la acentuación es un proceso distinto en el mapudungun.

De acuerdo con las afirmaciones de Smeets (2008) y Zúñiga (2007), en el mapudungun, el acento prosódico desempeña un papel mucho más limitado que en el castellano. En el español, de manera general, se acepta que las palabras funcionales no se acentúan mientras que las de contenido sí. Al parecer, en el mapudungun, las palabras no se acentúan a base de su función gramatical o léxica. Zúñiga asevera que en el mapudungun el acento principal de una palabra tiende a recaer en la última o penúltima sílaba de la mayoría de las palabras y que, en general, la acentuación depende del que una sílaba sea abierta o cerrada. Las cerradas, o las que terminan en semivocal o consonante en lugar de vocal, tienden a atraer el acento principal (Zúñiga 2007, p. 64). Según Smeets, existe la tendencia de acentuar la última vocal que vaya seguida por consonante. Sin embargo, esto puede cambiar según la cantidad de sílabas que tenga una palabra y, en los casos de palabras más largas, es posible que más de una sílaba se acentúe. De tal manera, Smeets afirma que el acento principal recae en la segunda vocal de la palabra, y el secundario recae sobre la última vocal. Zúñiga (2007) refuta esa noción y dice que, en estos casos, la penúltima sílaba es la que recibe el acento principal, y que la acentuación secundaria ocurre ya sea en la primera o segunda sílaba de la palabra. Aunque estos autores no están en completo acuerdo con las reglas de acentuación del mapudungun, ninguno hace mención de un proceso de acentuación que distinga palabras o morfemas funcionales de las que tienen un papel léxico, por lo que es difícil concluir que siquiera existe una relación entre la acentuación y las palabras o morfemas de función y contenido en el mapudungun. En términos generales, la distribución y la función del acento prosódico son distintas en el español y el mapudungun.

Sin embargo, aún podría argüirse que el comportamiento prosódico de los ascensos iniciales en ambas lenguas demuestra que, en ocasiones, los hablantes no observan las reglas de acentuación establecidas de sus respectivos idiomas cuando producen las mesetas. Aunque el acento prosódico no está tan estrechamente vinculado con la función de las palabras en el mapudungun, como ya se expuso, tiende a favorecer las sílabas abiertas. Sin embargo, se observaron casos en que la frecuencia fundamental ascendió en sílabas cerradas cuya ubicación no suele atraer el acento prosódico (véase la figura 13). No es evidencia bastante contundente, pero pese a que la relación entre el acento prosódico y la entonación en las dos lenguas es diferente, indica 
que es posible en ambas descartar las normas que generalmente rigen esa relación para iniciar una meseta. Además, respalda más la idea propuesta por Rogers $(2013,2016)$ de que la producción de estos contornos depende más de los deseos comunicativos de los locutores y no de reglas prescritas por sus respectivas gramáticas.

Al nivel sintáctico, los ascensos podían ocurrir al principio o en medio de sintagmas que se componían de más de un nódulo. En las figuras 16 y 17 , se aprecian mesetas de ambas lenguas que inician en determinantes que ocupan los primeros nódulos de sus respectivos sintagmas nominales. En la figura 16, la frecuencia fundamental empieza a aumentar en el morfema $t a$ que funciona para comunicar énfasis y en la figura 17, el ascenso inicial comienza en el determinante las.

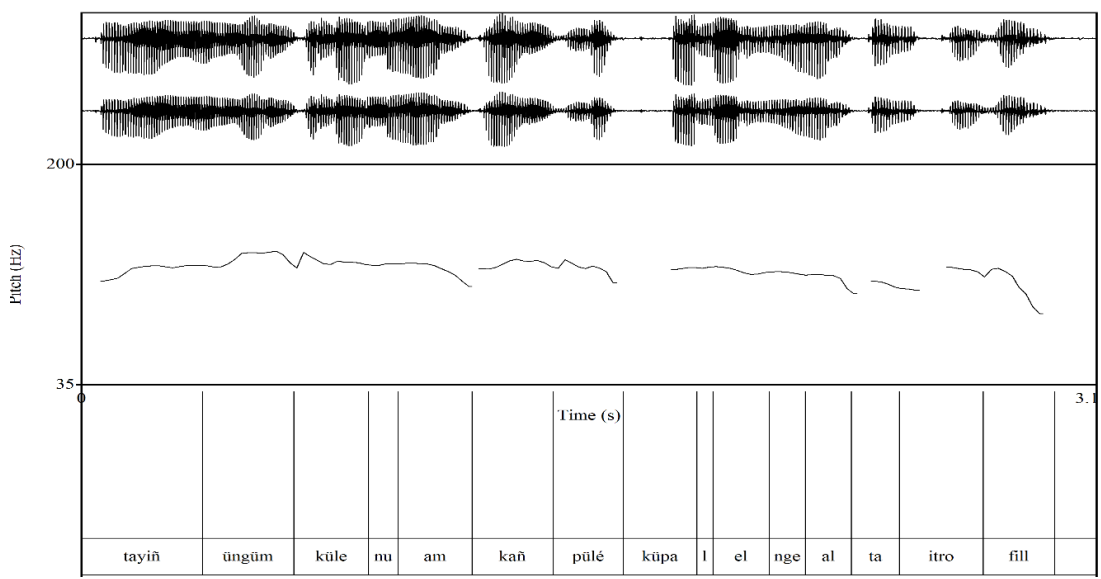

Figura 16: Meseta del mapudungun que inicia en un determinante “...tayiñ üngümkülenuam kañ püle küpalelngeal ta itrofill...” (“...No esperamos hasta que se [nos] traiga todo de afuera/otras partes...”) 


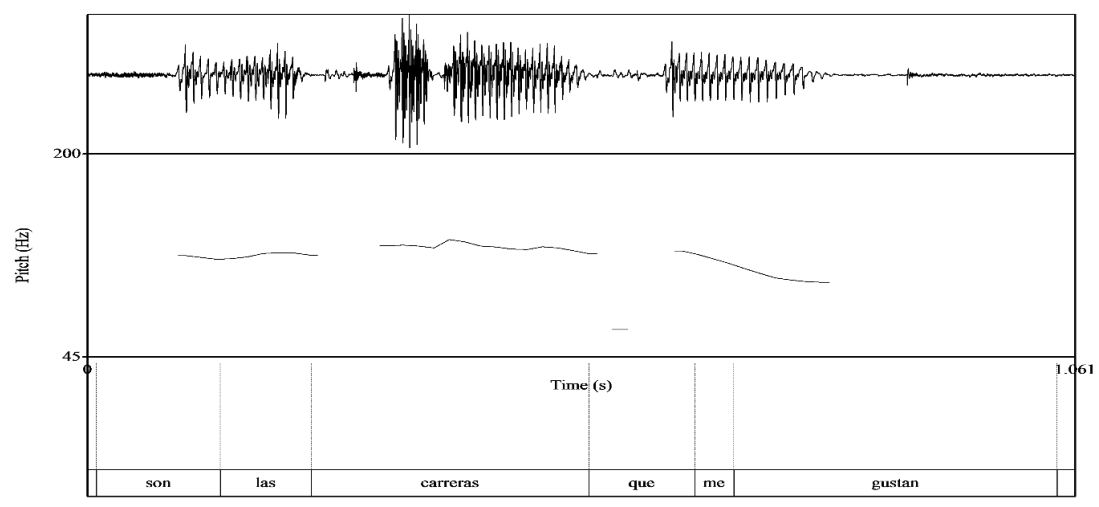

Figura 17: Meseta del castellano que inicia en un determinante "...son las carreras que me gustan..."

En los casos en que el acenso empezó en el segundo nódulo de un sintagma, el primero efectivamente se quedó en la porción baja, fuese acentuado o no, como se ve a continuación en las figuras 18 y 19.

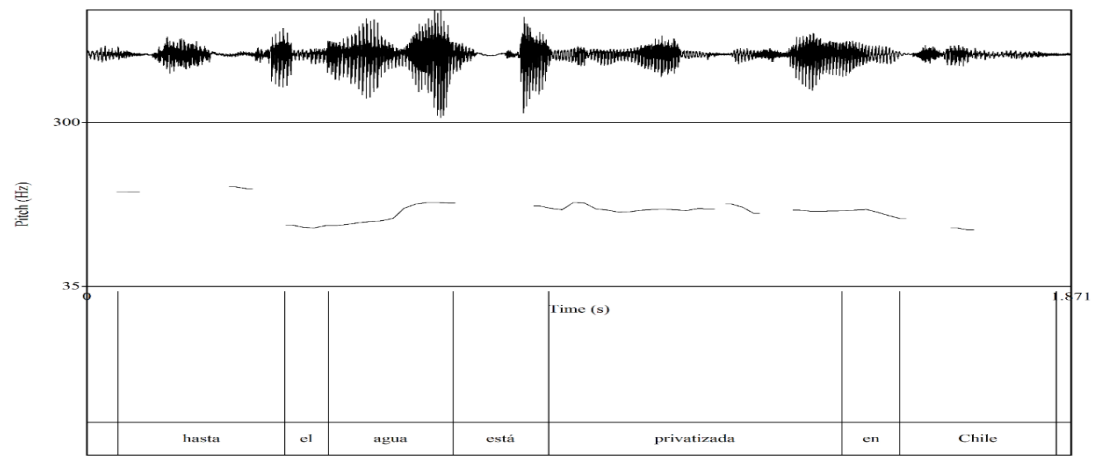

Figura 18: Meseta del castellano con un sintagma nominal dividido en el acenso inicial "...hasta el agua está privatizada en Chile...” 


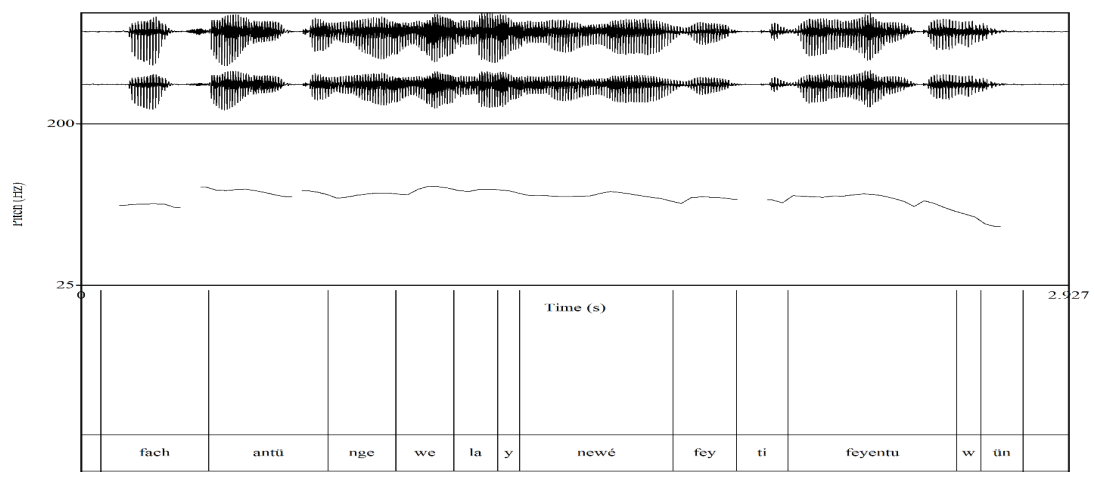

Figura 19: Meseta del mapudungun con un sintagma nominal dividido en el acenso inicial "...fachantü ngewelay newe feyti feyentuwün...” (“...ya no hay tanta confianza...”)

En la figura 18 no se aprecia ninguna trayectoria tonal ascendiente hasta después del artículo definido el. El ascenso ocurre en las dos sílabas del sustantivo agua, después de lo cual el locutor prosigue a la porción alta del contorno. Puesto que el mapudungun es aglutinante, en algunos casos puede ser problemática la tarea de aplicarle las mismas reglas sintácticas que se emplean para el castellano. Sin embargo, en el ejemplo de la figura 19, se presenta la palabra fachantü (lit. este día) que etimológicamente consiste en dos morfemas, fachi de tüfachi ("este") y antü (día/sol) que de forma etimológicamente subyacente podrían formar dos nódulos, determinante y sustantivo, de un sintagma nominal. Como se puede observar, el ascenso no se da hasta después del artículo, subiendo al nivel tonal de la porción alta casi de manera inmediata en la primera sílaba de antü.

\subsection{ConteXto PRAGMÁtico}

Quizás lo que más distingue las mesetas de la presente investigación es que éstas parecen ocurrir en contextos de foco amplio, mientras que en otros dialectos del español se limitan únicamente a contextos interrogativos. Es decir, en los contextos en que tanto hablantes del mapudungun, así como del español chileno, producen las mesetas de la presente investigación, se considera que todo el contenido del que se componen goza del mismo grado de importancia, ya que los locutores no parecen hacer ningún esfuerzo por colocar ningún elemento léxico individual de relieve mayor. En la figura 20 , se observa una meseta del mapudungun de menor tamaño extraída de Olate (2015). 


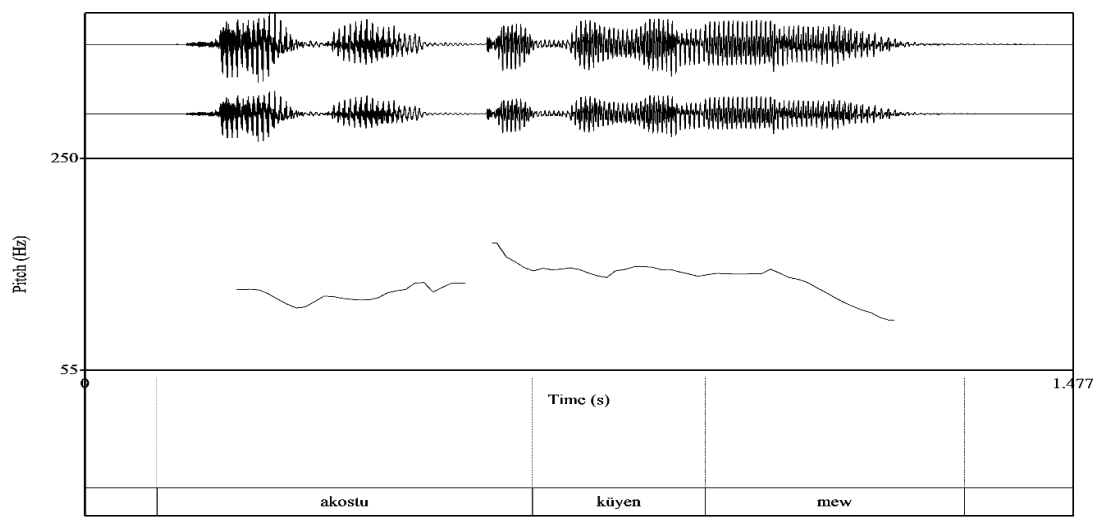

Figura 20: Meseta del mapudungun en un contexto con apariencia de foco amplio “...akostu küyen mew..." (...[mi cumpleaños] es en agosto...”)

Esta meseta viene de un sencillo y breve intercambio entre dos individuos en el que se le pregunta al locutor cuándo cumple años, la respuesta de este último forma la meseta de la figura 20. Esta información es completamente nueva para el oyente, ya que, según el contexto, el otro individuo no tiene conocimiento previo respecto al tema. Además, al nivel prosódico, el locutor no parece brindarle un grado mayor de importancia contextual a ninguna de las tres palabras contenidas en la meseta mediante la entonación. Es decir, no produce ningún pico entonativo en ninguna sílaba individual para así distinguirla de las demás. Dadas estas observaciones, a lo que más viene pareciéndose la afirmación en la figura 20 , es a una aseveración de foco amplio, ya que no puede ser de foco estrecho.

A continuación, la figura 21 muestra un ejemplo de una meseta de tamaño reducido del castellano que también presenta comportamiento de índole similar. Previo a la figura se encuentra una transcripción de la porción correspondiente de la conversación con el contenido de la meseta en negrillas mayúsculas. Cabe notar que esta porción contiene dos mesetas, la primera aparece en letras mayúsculas sin negrillas.

INVESTIGADOR: “¿Cuál es tu turno?”

LOCUTOR: "Eee...nocturno. Si, nocturno, y aparte hago mis pololitos DOS VECES A LA SEMANA. En el día, en el día. Por ejemplo, ee, LAVAR LOS BUSES. 


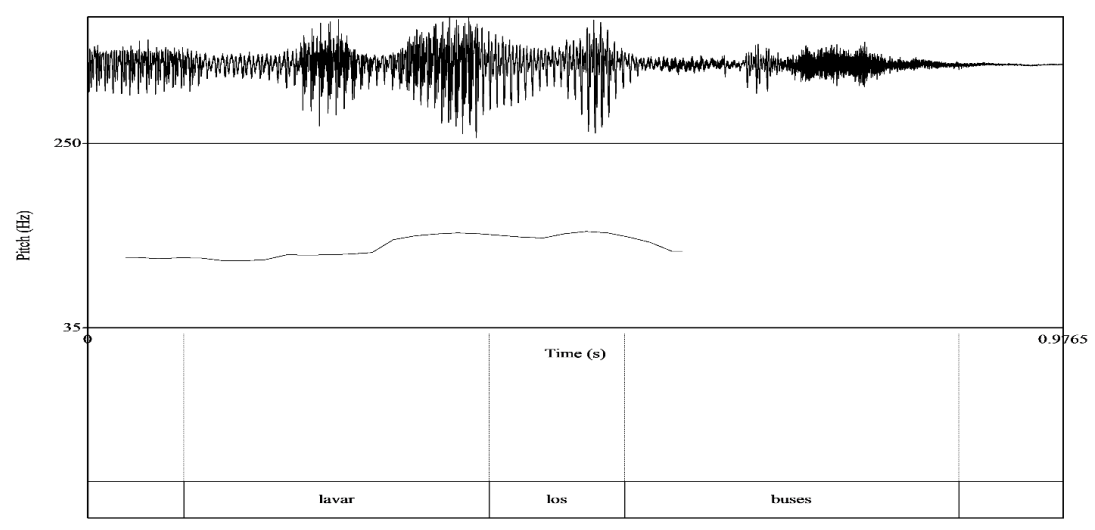

Figura 21: Meseta del castellano de un contexto con apariencia de foco amplio "...lavar los buses..."

$\mathrm{Al}$ igual que el ejemplo anterior del mapudungun, esta meseta solo cuenta con tres palabras. A estas alturas de la conversación, el investigador le había preguntado al participante por unos detalles de su trabajo, información que ignoraba antes de grabar la conversación. Al analizar la curva de la frecuencia fundamental, no resalta ningún movimiento tonal en ninguna sílaba que indique que el locutor la considera de mayor importancia o merecedora de foco más estrecho que las demás sílabas.

En la figura 22, se aprecia una meseta del mapudungun (Smeets 2008) que se produjo en el contexto de un cuento sobre las creencias sobrenaturales mapuches respecto a los demonios, o pu weküfu. Lo que sigue es una transcripción en español de la porción correspondiente de la conversación. El contenido de la meseta aparece en negrillas mayúsculas.

Cuando los dueños del ganado se acuestan de noche, las almas ambulantes salen y se aseguran de que no se robe ni un animal. Se visten de manera muy elegante. A veces andan en caballo. Ambulan con espuelas grandes. De noche, brillan sus dientes. A veces les agrada manifestarse a personas que ambulan a solas. OTRO [demonio es] UN DEMONIO DE TAMAÑO MENOR. No crece... (Smeets 2008: 375; traducción al español propia de la traducción inglesa original). 


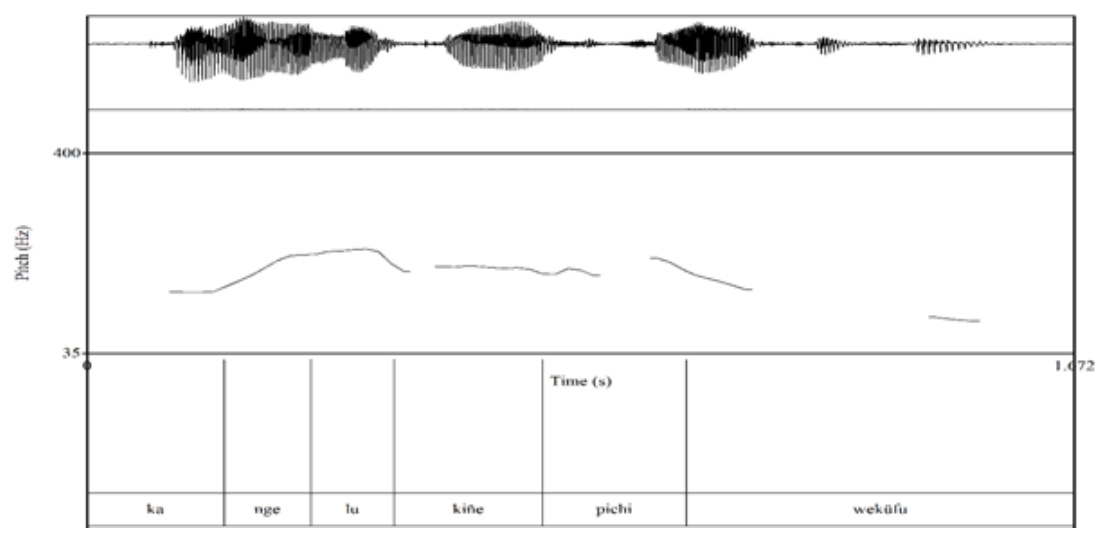

Figura 22: Meseta del mapudungun producida en un contexto con apariencia de foco amplio "...kangelu kiñe pichi weküfu..." (“...otro [demonio es] un demonio de tamaño menor...”)

En este trozo de conversación, el locutor comunica información que hasta dónde llega su saber, ignora la entrevistadora. El locutor termina de hablar de una especie de criatura sobrenatural e indica, en la porción de la conversación de la que se compone la meseta, que va a hablar de otra especie, un demonio. Prosódicamente, como en los casos anteriores, no ocurre ningún movimiento de la frecuencia fundamental que señale que el locutor hace mayor hincapié en alguna palabra y/o morfema en particular, lo cual sugiere, de nuevo, que el contexto se asemeja más a una afirmación de foco amplio.

El ejemplo que sigue en la figura 23 viene de una conversación del español. A continuación, figura una transcripción de la porción correspondiente de la conversación con el contenido de la meseta en negrillas mayúsculas.

LOCUTOR: "Sí...ellos no terminan de crecer a los dieciocho, po. Ellos no van a tener su poder de decisión hasta que no se casen y adquieran sus cosas, po."

INVESTIGADOR: "Y, ¿alguna vez han, han r-, han entrado a robar, a robar a la iglesia?"

LOCUTOR: "Sí, varias- (breath) Lo que PASA ES QUE ANTES HABÍAN ENTRADO A ROBAR VARIAS VECES. Pero ya, como pusieron rejas de seguridad y puertas dobles de..de acero, ya no entran, poh." 


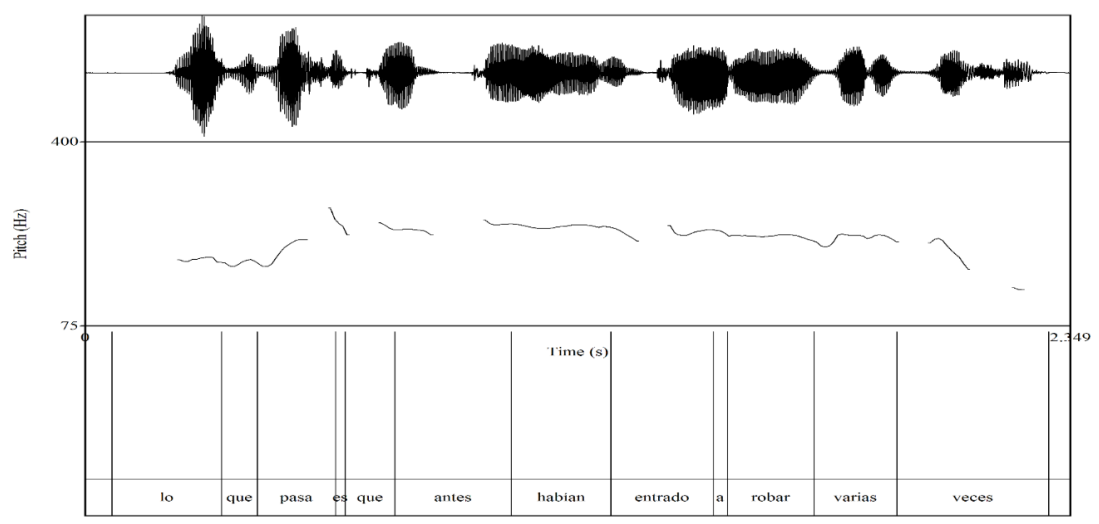

Figura 23: Meseta del español que figura en un contexto con apariencia de foco amplio "...lo que pasa es que antes habían entrado a robar varias veces..."

A estas alturas de la conversación, el locutor, que residía en Candelaria, relataba algunas de las estrategias que ejercía para que sus hijos no se dejaran llevar por algunas de las malas influencias, tales como la droga y el robo, que son problemáticas en algunos sectores de dicha población. Interesado en el tema, el investigador indaga para ver si alguna vez, alguien había intentado ingresar a la iglesia del locutor con la intención de robar. La respuesta del locutor a esta interrogante forma la mayoría de la meseta de la figura 23. Similar al ejemplo de la figura 22, el contenido de la meseta es información nueva en el contexto de la conversación y el locutor no parece asignarle un mayor grado de prominencia prosódica o pragmática a ninguna palabra. Por consiguiente, al igual que los casos que ya se han expuesto, su contexto pragmático también parece ser de foco amplio.

\section{IMPLICACIONES}

\subsection{Según La EVIDENCIA EXISTENTE ¿QUÉ PAPEL COMUNICATIVO PUEDEN DESEMPEÑAR LAS MESETAS ENTONACIONALES EN LAS DOS LENGUAS? ¿SE DEBE SU USO AL CHILENO AL CONTACTO LINGÜÍSTICO CON EL MAPUDUNGUN?}

Cuando se consideran todas las características compartidas de las mesetas de ambas lenguas, la evidencia sugiere que estas tienen un origen y uso comunes. Debido a que la relación entre el pueblo mapuche y el Estado 
chileno ha sido siempre turbulenta, se hace difícil la tarea de estudiar los efectos lingüísticos del contacto que ha habido entre el mapudungun y el español chileno. Lamentablemente, aparte de engendrar estigmas sociales hacia el pueblo mapuche dentro de Chile, esta relación tensa ha afectado las actitudes de algunos lingüistas hacia su lengua. Resulta probable que la oposición que Lenz y su teoría araucanista tuvieron que enfrentar se haya arraigado, en parte, en el eurocentrismo y la discriminación hacia los pueblos amerindios. Como consecuencia, existe una escasez de estudios de las dos lenguas durante períodos en los que el contacto cultural y lingüístico fueron mucho mayores de lo que se observa hoy. Debido a la actual carencia de datos sincrónicos como diacrónicos, resultaría problemático determinar los orígenes de cambios en ambas lenguas como consecuencia del contacto lingüístico, si algo detuvo su progreso o si se fosilizaron. Sin embargo, existe suficiente evidencia como para aseverar que hubo una época de contacto cultural y social intensos entre los integrantes de ambas comunidades lingüísticas. Thomason y Kaufman (1988) afirman lo siguiente con respecto a los requisitos para determinar si un fenómeno en una lengua se debe al contacto con otra lengua:

Una metodología adecuada ... requiere examinar una situación como si ésta fuese un bosque en vez de una colección de árboles en aislamiento. Para respaldar una afirmación de que el rasgo X surgió en la lengua $\mathrm{A}$ bajo la influencia de la lengua $\mathrm{B}$, es necesario verificar que la presencia de los rasgos a,b,c,y,z-al menos algunos de los cuales provenientes de un subsistema distinto al que contiene $\mathrm{X}$-también surgieron en la $\mathrm{A}$ como consecuencia de la influencia de la B. (Thomason y Kaufman 1988: 61; traducción propia del autor)

Pese a la escasa evidencia, estudios recientes como Sadowsky (2013) y Sadowsky y Aninao (2013) indican que es posible que la influencia del mapudungun en el castellano chileno haya tenido un alcance mayor de lo que hasta ahora se ha afirmado, provocando cambios en algunos de los subsistemas más profundos de la lengua. Si tal noción es verdadera, entonces, de acuerdo con lo que aseveran Thomason y Kaufman (1988), sí existen rasgos en el español chileno que parecen ser contribuciones del mapudungun, por lo que resulta aún más posible que la presencia de las mesetas entonacionales analizadas en este estudio provenga del mapudungun también.

Hasta ahora no existe evidencia perceptual para confirmar con acierto la función de las mesetas entonacionales de la presente investigación. Sin embargo, a base del comportamiento ya mencionado, es posible plantear algunas posibilidades. Ya que aparecen categóricamente en contextos con 
apariencia de foco amplio, una primera posibilidad es que sean meramente una realización alofónica de declarativas de foco amplio. Según lo que se ha informado respecto al castellano chileno, en su mayoría, las afirmaciones declarativas de foco amplio se realizan con escalonamiento. Es decir, ocurre una cumbre tonal en cada sílaba acentuada cada vez más baja que la anterior, como se aprecia en la figura 24 de Rogers (2016).

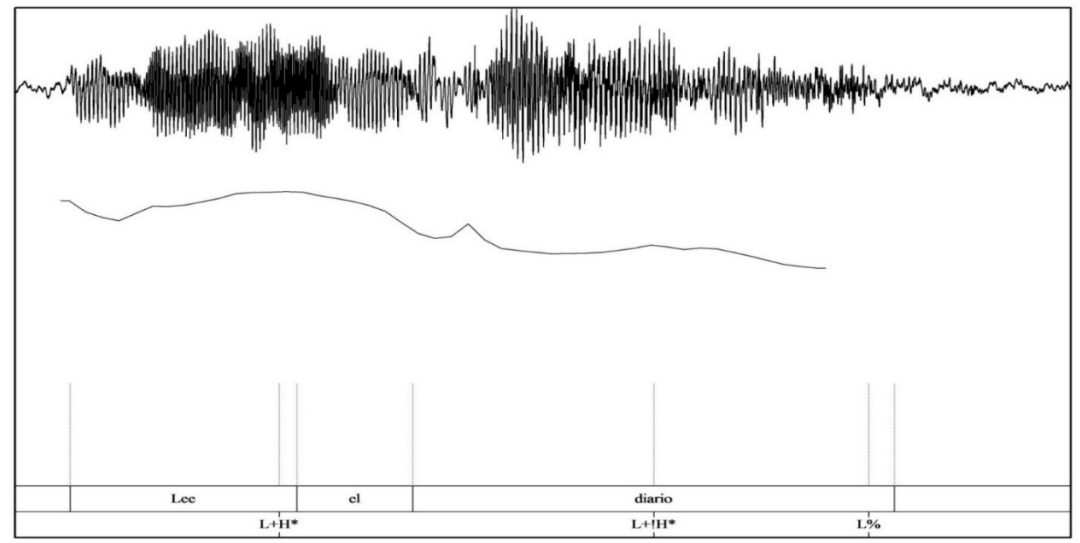

Figura 24: Una declarativa de foco amplio del castellano chileno "lee el diario".

Por el hecho de que las mesetas observadas en este estudio ocurran únicamente en contextos con un foco amplio, es posible argüir que son una alternativa puramente fonética para realizar una aseveración de foco amplio. Si este resulta ser el caso, el español chileno sería la única variedad del español que utilizara la forma fonética de una meseta para expresar afirmaciones de foco amplio. Aunque la evidencia existente sigue siendo escasa, dado que en el mapudungun las mesetas ocurren en el mismo contexto pragmático, podría argüirse de manera preliminar que, por el contacto que tuvieron las dos lenguas en una época anterior, las mesetas eventualmente se introdujeron a la fonética entonacional del español chileno como forma alofónica para la expresión del foco amplio. Sin embargo, este argumento no toma en cuenta lo que ya se ha aseverado respecto al papel pragmático de los ascensos tonales y el foco amplio en el español, ni tampoco toda evidencia ya presentada en estudio.

Una variedad de estudios (p.ej. Face 2003, Rao 2009) anteriores ha afirmado que el uso de un registro tonal más alto tiene como papel destacar la porción del enunciado en la que ocurra. Es decir, el uso de un registro tonal alto del tipo observado en las mesetas del mapudungun y el español chileno es una forma de enfatizar una porción de una idea en el castellano. 
En el español, las afirmaciones de foco amplio no suelen ser un mecanismo para comunicar énfasis. Así que, aunque las mesetas del presente estudio se producen estrictamente en contextos que tienen apariencia de foco amplio, el uso de un registro tonal alto destaca su contenido de tal forma que resulta poco probable que un locutor de cualquiera de las dos lenguas emplease una meseta para comunicar una simple afirmación de foco amplio. Más bien, el uso delibrado de un registro tonal notablemente más alto indica que es más probable que sean un mecanismo para destacar la idea o el concepto que contienen. Además, cuando se considera este hecho con la variación de la extensión de la porción alta que se aprecia en las dos lenguas, esto también revela que no son meramente una forma alternativa de expresar el foco amplio.

El comportamiento prosódico y sintáctico observados en las mesetas de ambas lenguas señalan una tendencia de priorizar la inclusión de conceptos más detallados y complejos en las mesetas en lugar de elementos léxicos más sencillos. Una consecuencia de esta tendencia es que los locutores en ocasiones descartan reglas que normalmente rigen la sintaxis y la distribución del acento prosódico de sus lenguas respectivas. Es decir, en el castellano, los locutores aumentan la frecuencia fundamental en contenido que normalmente carece de él y se considera presente únicamente al nivel fonético; y en el mapudungun, los locutores inician los ascensos en sílabas cerradas cuya ubicación dentro de una palabra normalmente no atrae el acento. En condiciones normales, no se esperaría observar ascensos perceptibles en estos puntos del enunciado con la frecuencia que ocurren en las mesetas. Esto no significa que los hablantes del castellano chileno y el mapudungun descarten por completo estas normas prosódicas y sintácticas, sino que éstas desempeñan un papel secundario ya que el principal lo ocupan la pragmática y las metas comunicativas de los locutores.

Cabe notar que en las muestras del castellano se observaron otras tendencias que apoyan la idea de que las mesetas son una forma de destacar conceptos más complejos y extensos y que su extensión depende en gran parte de los deseos comunicativos de los locutores. Primero, era común en los datos que los castellanohablantes mantuvieran el registro tonal elevado en las porciones altas hasta terminar con la idea que comunicaban aun cuando hubo interrupciones, autocorrecciones, tartamudeos y pausas para tomar aliento o pensar. Típicamente, después de una interrupción de esta índole, los locutores tienen la tendencia de reestablecer la frecuencia fundamental en un nivel tonal bajo (p.ej. De Pijper y Sanderman 1994, Lin y Fon 2011). De hecho, en los datos de la presente investigación, cuando los locutores hispanohablantes no producían mesetas entonacionales, era muy común que revirtiesen a un registro tonal más bajo al volver a tomar la palabra tras 
una interrupción en el discurso del tipo mencionado. Esto parecería sugerir que la comunicación completa del contenido de una meseta es lo que más priorizan los locutores, tanto que abandonan el comportamiento entonativo que típicamente presentan ante las interrupciones prosódicas si tal se hace necesario. La figura 25 muestra un caso de castellano en el que locutora mantiene la porción alta a través de dos pausas hasta terminar de transmitir toda la idea que comunicaba.

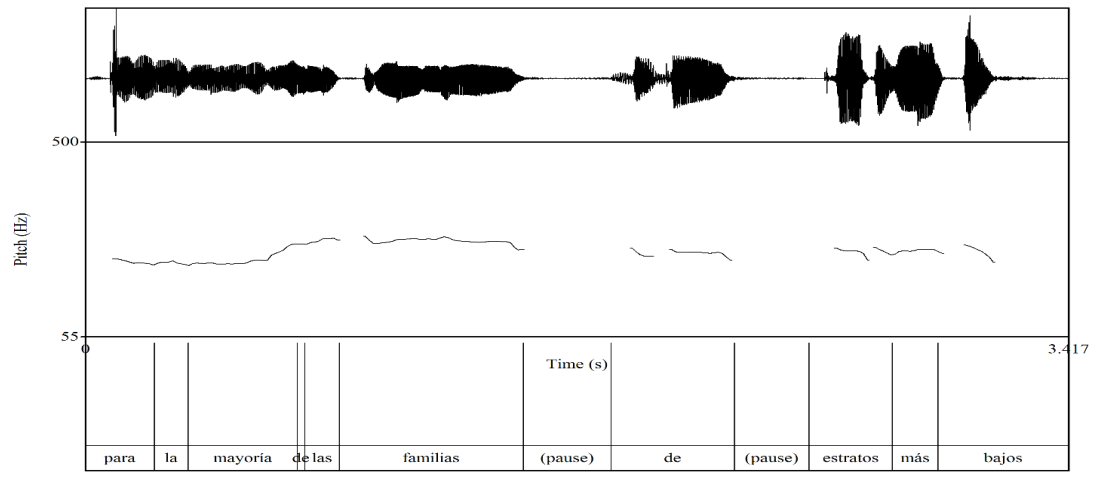

Figura 25: Meseta del castellano mantenida a través de dos pausas "...para la mayoría de las familias, de, estratos más bajos..."

Por último, también se observó en el castellano que a veces una meseta entonacional podía contener más de un enunciado si era de la misma idea que el locutor pretendía comunicar, como se ve en la figura 26.

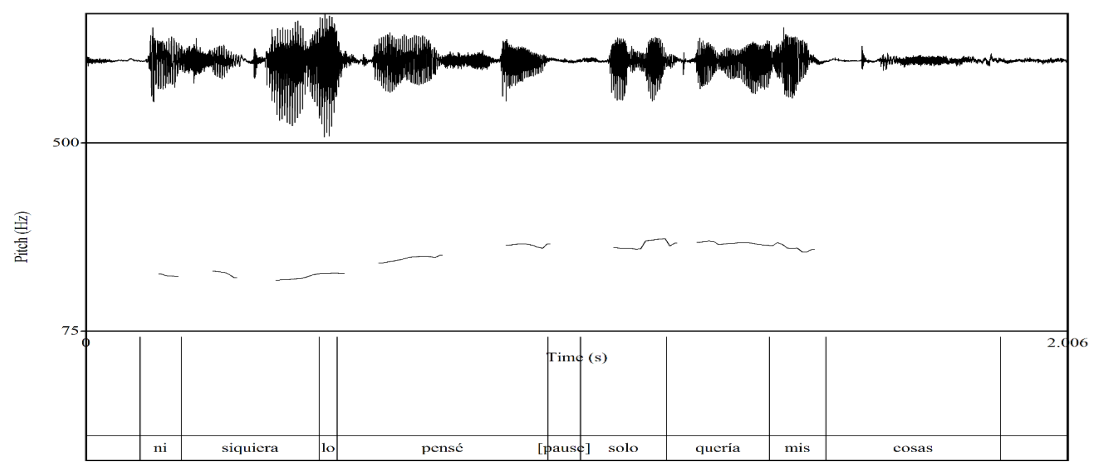

Figura 26: Meseta del castellano que contiene dos enunciados "Ni siquiera lo pensé. Sólo quería mis cosas." 
La entonación se considera más moldeable y superficial que otros subsistemas lingüísticos, por lo que no es necesario que haya un contacto tan prolongado e intenso entre dos comunidades lingüísticas para que se realicen cambios en el sistema entonacional de por lo menos una de ellas (p.ej. O'Rourke 2005, Simonet 2011, Alvord 2010, Colantoni 2011). Cuando el contacto entre lenguas provoca algún cambio entonacional, rara vez resulta en la introducción de formas o contornos entonativos que antes no existían en la lengua receptora. Más bien, lo que se ha documentado en una mayoría de casos de este tipo es que formas entonacionales ya existentes, antes utilizadas para comunicar un significado específico en la lengua receptora, tal como la alineación temprana de picos tonales (O’Rourke 2005, Colantoni 2011), empiezan a emplearse en la transmisión de un significado que proviene de la lengua donadora.

Sobre la base de las tendencias y los datos presentados en esta investigación, se propone que las mesetas analizadas del mapudungun y el castellano chileno tienen como función pragmática y comunicativa la extensión del foco para poner de relieve la prominencia de una idea completa o una secuencia de palabras acentuadas, a menudo sintáctica y semánticamente complejas. Bien es cierto que es necesario obtener y evaluar datos perceptuales de hablantes nativos de ambas comunidades lingüísticas para confirmar si las mesetas son un mecanismo de foco extendido. Sin embargo, el comportamiento y las similitudes presentados señalan una tendencia general, tanto en hablantes del mapudungun como en los del castellano chileno, de enfatizar de manera deliberada ideas y conceptos más complejos y extensos como unidades singulares. Ya que se ha demostrado que, en términos más generales, el español permite la producción de mesetas entonativas, resulta muy poco probable que el mapudungun introdujese las mesetas al sistema entonacional del español chileno como forma fonética innovadora. Más bien, lo que propone esta investigación es que el mecanismo pragmático y comunicativo de la extensión del foco discursivo mediante la forma fonética de las mesetas es lo que se ha incorporado al español chileno como consecuencia del contacto con el mapudungun.

\section{2. ¿CUÁLES SON LAS IMPLICACIONES PARA LA TEORÍA ARAUCANISTA DE LENZ?}

La teoría de Lenz investiga el tema de la influencia del mapudungun en el castellano chileno principalmente desde un marco fonético. Como señalan Oroz (1966) y Alonso (1953), Lenz no examinó con mucho esmero los sistemas entonativos respectivos de estas lenguas. Por consiguiente, aunque 
algunos de sus opositores afirmaron que existe una gran probabilidad de que la prosodia y la entonación del castellano chileno cuenten con influencias del pueblo mapuche, hasta la fecha el tema no se ha analizado en detalle. Usando la evidencia del presente estudio, es posible modificar la teoría de Lenz para dar cabida al estudio de la influencia del mapudungun en los subsistemas prosódicos del español chileno. Las mesetas entonacionales son apenas un contorno que forma parte del inventario entonacional chileno y aún es posible que otros contornos y aspectos del español chileno tengan sus orígenes en la entonación del mapudungun. Por ejemplo, en la muestra del castellano del presente estudio, en ciertos contextos interrogativos se produjeron contornos del tipo que aparece en la figura 27.

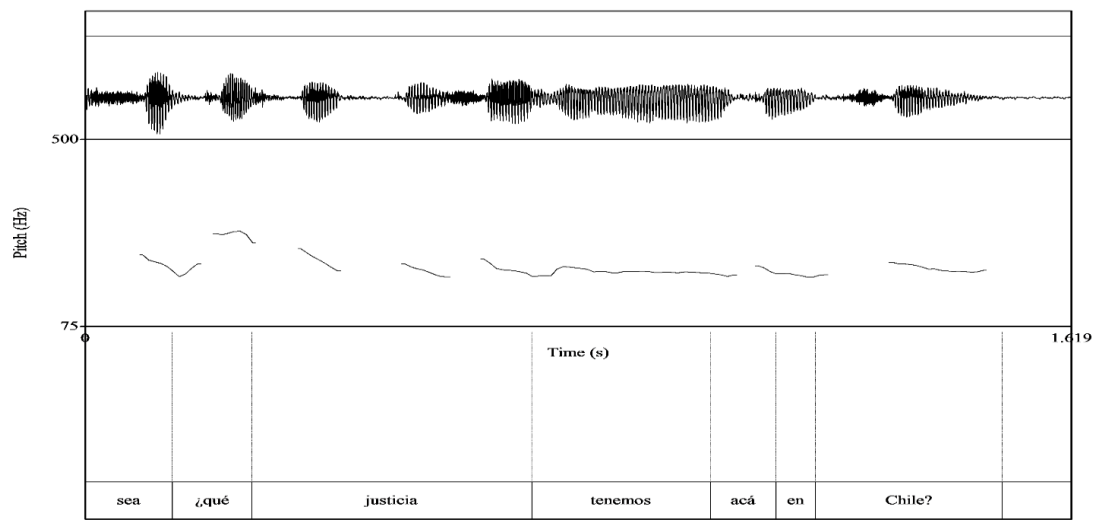

Figura 27: Contorno interrogativo del castellano

“...sea ¿qué justicia tenemos acá en Chile?"

En este tipo de contorno interrogativo, los locutores producen un pico tonal abrupto en la palabra interrogativa y después la frecuencia fundamental baja y se mantiene en el mismo registro bajo y casi monótono hasta el final de la pregunta, cubriendo una extensión relativamente larga y variada de contenido. Ortiz et al. (2010) también proporcionan un ejemplo de este tipo de contorno interrogativo que parece ser un comportamiento entonativo muy específico del español chileno, ya que no parece emplearse en otros dialectos. Asimismo, Fuentes (2012) informa que las peticiones en el castellano chileno cuentan con rasgos entonacionales particulares que parecen ser característicos de los chilenos. Todas estas peculiaridades respaldan la afirmación de Oroz (1966) de que la entonación chilena difiere de manera notable de la de otros dialectos del español. Como consecuencia, amerita investigar la posibilidad de que esos rasgos singulares de la entonación chilena sean el resultado del contacto con el mapudungun. 


\section{CONCLUSIONES}

Debido a que la producción de mesetas entonacionales se observa de manera tan extendida en el habla de tantos hispanohablantes chilenos, cabe postular que la extensión del foco, como mecanismo pragmático y discursivo, se introdujo al castellano de la región desde una época muy temprana; específicamente después de que el pueblo mapuche y el chileno empezaron a tener un nivel de contacto cultural más o menos regular e intenso. Por consiguiente, es probable que como cambio lingüístico ya haya llegado a término. Una posibilidad es que este fenómeno, y cualquier otro fenómeno lingüístico del castellano chileno que pueda atribuirse al contacto con el mapudungun, hayan ocurrido con anterioridad a la dictadura militar y el golpe del 1973, los cuales condujeron a que muchos mapuches buscaran refugio en diferentes sectores de Chile y en el extranjero (Smeets 2008). Por causa de la continua represión del pueblo mapuche, aun después de la dictadura, se ha limitado el contacto postdictadura entre la sociedad chilena y los mapuche, por lo que puede ser más difícil documentar cambios lingüísticos en tiempo real.

A la luz de los hallazgos arrojados por los estudios de Sadowsky (2013) y Sadowsky y Aninao (2013), las aseveraciones originales de la teoría de Lenz todavía pueden confirmarse y la oposición que ha tenido que enfrentar durante más de un siglo puede refutarse con mayor seguridad. Con lo que este estudio contribuye al debate es con la necesidad de una ampliación de los parámetros de dicha teoría para incluir la investigación de la entonación, y en términos más generales, de la prosodia, del mapudungun y el castellano chileno. Son demasiadas las similitudes entre las mesetas de las dos lenguas y fue demasiado el contacto cultural, social y lingüístico entre el pueblo mapuche y el chileno como para simplificar la presencia y el uso de estos contornos entonativos en ambas lenguas a un producto de la casualidad.

\section{REFERENCIAS BIBLIOGRÁFICAS}

AdelaAr Willem F. H. (en colaboración con Pieter C. Myusken). 2004. The Languages of the Andes. Cambridge: Cambridge University Press.

Alonso, Amado. 1953. Estudios lingüisticos: Temas hispanoamericanos. Madrid: Gredos.

Amado Alonso y Raimundo Lida (eds.). 1940. Biblioteca de dialectología hispanoamericana: El español en Chile. Buenos Aires: Universidad de Buenos Aires. 
Alvord, Scott M. 2010. Variation in Miami Cuban Spanish Interrogative Intonation. Hispania 93(2): 235-255.

Armstrong, Megan E. 2010. Puerto Rican Spanish Intonation. En Pilar Prieto y Paolo Roseano (eds.), pp. 155-189.

Astruc Lluïsa, Mora Elsa y Rew Simon. 2010. Venezuelan Andean Spanish Intonation. En Pilar Prieto y Paolo Roseano (eds.), pp.191-226.

Barker, Geoffrey. 2005. Intonational Patterns in Tyrolean German: An Autosegmental Metrical Analysis. New York: Peter Lang.

Boersma, Paul y Weenink David. 2015. Praat: Doing phonetics by computer, versión 5.3.84 [software]. Disponible en http://www.praat.org [consulta 04/30/2016].

Cabrera, Mercedes A., y Francisco O. Vizcaíno. 2010. Canarian Spanish Intonation. En Pilar Prieto y P. Roseano (eds.), pp. 191-226.

CePeda, Gladys. 1997. Las unidades entonacionales del habla de las mujeres de Valdivia, Onomazein 2: 83-110.

Cid, Miriam E. y Héctor Ortiz. 1998. La conducta prosódica del vocativo en el español culto de Santiago de Chile. Onomázein 3: 143-162.

Clopper, Cynthia G. y Judith Tonhauser. 2011. On the Prosodic Coding of Focus in Paraguayan Guaraní. En Mary Washburn, Katherine McKinney-Bock, Erika Varis, Ann Sawyer y Barbara Tomaszewicz (eds.), pp. 249-257.

Colantoni, Laura. 2011. Broad-focus declaratives in Argentine Spanish contact and noncontact varieties. En Christoph Gabriel y Conxita Lleó, (eds.), pp.183-212.

Comisión nacional del XVII Censo de la Población y VI de Vivienda. 2002. Censo 2002: Sintesis de Resultados. Disponible en http://www.ine.cl/docs/default-source/ FAQ/s\%C3\%ADntesis-de-resultados-censo-2002.pdf?sfvrsn=2 [Consulta 24/08/2017].

Croese, Robert A. 1985. Mapuche Dialect Survey. En Harriet E. Manelis Klein y Louisa R. Stark (eds.), pp. 753-81.

Cruz-Coke, Ricardo, y Rodrigo S. Moreno. 1994. Genetic epidemiology of single gene defects in Chile. Journal of Medical Genetics 31: 702-706.

De PiJPer, JAN Roelof y ANGelien SANDERman. 1994. On the perceptual strength of prosodic boundaries and its relation to suprasegmental cues. The Journal of the Acoustical Society of America 96: 2037-2047.

ELORDIETA, GORKA. 2003. The Spanish intonation of speakers of a Basque pitch-accent dialect. Catalan Journal of Linguistics 2: 67-95.

Face, Tiмотну. L. 2003. Intonation in Spanish declaratives: Differences between lab speech and spontaneous Speech. Catalan Journal of Linguistics 2:115-131.

FÉry, CARoline. 1993. German Intonational Patterns. Tübingen: Niemeyer.

Fuentes, Marcela. 2012. Análisis fonético-acústico de la conducta prosódica de los enunciados del tipo imperativo (petición y orden) del español de Santiago de Chile. Tesis para optar al grado de Magíster con mención en Lingüística Hispánica, Pontificia Universidad Católica de Chile.

Gabriel, Christoph, Ingo Feldhausen y Andrea PešKová. 2011. Prosodic Phrasing in Porteño Spanish, en Christoph Gabriel C. y Conxita Lleó (eds.), pp.153-182.

Gabriel, Christoph y Lleó ConXita (eds.). 2011. Intonational phrasing at the interfaces: cross-linguistic and bilingual studies in Romance and Germanic. Amsterdam: John Benjamins.

Hualde, José I., y Armin Schwegler. 2008. Intonation in Palenquero. Journal of Pidgin and Creole Languages (23)1: 1-31.

Klein-Andreu, Flor (ed.). 1994. Discourse Perspectives on Syntax. New York: Academic Press. 
LADD, Robert. 2008. Intonational Phonology, $2^{\mathrm{a}}$ ed. New York: Cambridge University Press.

Lenz, Rodolfo. 1940. El español en Chile. En Amado Alonso y Raimundo Lida (eds.), pp. 39-268.

LIN, HSIN-YI Y FON, JANICE. 2011. The role in pitch reset in perception at discourse boundaries. ICPhS XVII: 1242-1245.

Manelis, Klein H. E., y Louisa R. Stark (eds.). 1985. South American Indian Languages: Retrospect and Prospect. Austin: University of Texas Press.

Olate, Aldo. 2015. Colección personal de entrevistas en mapudungun [Consulta 16/02/2016].

O'ROURKe, ERIN. 2005. Intonation and language contact: a case study of two varieties of Peruvian Spanish. Tesis para optar al grado de Doctor en Fliosofía con mención en Lingüística Hispánica, Universidad de Illinois, Champaign-Urbana.

Oroz, Rodolfo. 1966. La lengua castellana en Chile. Santiago: Universidad de Chile.

Ortiz, Héctor, Marcela Fuentes y Llüisa Astruc. 2010. Chilean Spanish intonation. En Pilar Prieto y Paolo Roseano (eds.), pp. 255-283.

PéRez, Susana. 2015. La entonación del español de Galicia desde una perspectiva sociofonética. Tesis para optar al grado de Doctor en Filosofía con mención en Lingüística Hispánica, Universidad de Minnesota.

Prieto, Pilar y Roseano, Paulo (eds.). 2010. Transcription of Intonation of the Spanish Language. Munich: Lincom Europa.

Quilis, ANTONio. 1999. Tratado de fonología y fonética españolas. 2a ed. Madrid: Gredos.

Rocco, Paola, Carmen Morales, Mauricio Moraga, Juan Nervi Miquel, Elena Flavio Llop y Francisco RothHammer. 2002. Composición genética de la población chilena. Distribución de polimorfismos de DNA mitocondrial en grupos originarios y en la población mixta de Santiago. Revista Médica de Chile 130(2), Disponible en http://dx.doi. org/10.4067/S0034-98872002000200001 [Consulta 15/08/2013].

Rao, Rajiv. 2009. Deaccenting in spontaneous speech in Barcelona Spanish. Studies in Hispanic and Lusophone Linguistics 2(1): 31-75.

Rogers, BRANDON M. A. 2013. The extent of tonal events: Intonational hat patterns in Chilean Spanish. Estudios de Fonética Experimental 22: 171-192.

2016. When Theory and Reality Collide: Exploring Chilean Spanish Intonational Plateaus. Tesis para optar al grado de Doctor en Filosofía con mención en Lingüística Hispánica, Universidad de Minnesota.

Romera, Magdalena, y Gorka Eldorieta. 2013. Prosodic accommodation in language contact: Spanish intonation in Majorca. IJSL 221: 127-151.

SAdOwSKY, Sсотт. 2013. La influencia del mapudungun en el castellano de Chile: el caso de las vocales. Trabajo presentado en el III Encuentro de Lenguas Indígenas de América. Universidad Nacional de Río Negro, Bariloche, Argentina, 15-17 de mayo.

SADOWSKY, SCOTT Y MARÍA JosÉ ANINAO. 2013. Etnolecto, la variable negada: Inconcordancia de número en hablantes mapuches monolingües en castellano. Trabajo presentado en el XX Congreso Internacional de la Sociedad Chilena de Lingüística (SOCHIL). Universidad Católica de la Santísima Concepción, Concepción (Chile), 27-29 de noviembre.

Salas, Adalberto. 2001. El Mapuche o Araucano: fonología, gramática y antología de cuentos. Madrid: Mapfre.

SÁNCHEZ, GilBerTo. 1992. La contribución del Dr. Rodolfo Lenz al conocimiento de la lengua y cultura mapuches. Boletín de Filología 33: 273-299.

Silva-Corvalán, CARMEN. 1983. On the Interaction of Word Order and Intonation: Some OV constructions in Spanish. En Flor Klein-Andreu (ed.), pp.117-140.

1994. Language Contact and Change: Spanish in Los Angeles. Oxford: Clarendon Press. 
Simonet, Miquel. 2011. Intonation convergence in language contact: Utterance-final F0 contours in Catalan-Spanish early bilinguals. Journal of the International Phonetic Association 41: 157-184.

Smeets, IneKe. 2008. A Grammar of Mapuche. New York: Mouton de Gruyter.

Thomason, Sarah G. y Terrence Kaufman. 1988. Language Contact, Creolization, and Genetic Linguistics. Los Angeles: University of California Press.

UNPO. 2015. Unrepresented Nations and Peoples Organization, de Submission of the Unrepresented Nations and Peoples Organization to the Expert Mechanism on the Rights of Indigenous Peoples: Promotion and Protection of the Rights of Indigenous Peoples with Respect to their Cultural Heritage. Disponible en http://www.ohchr.org/Documents/ Issues/IPeoples/EMRIP/CulturalHeritage/UNPO.pdf [Consulta 04/02/2016].

Van Coetsem, Frans. 2000. A General and Unified Theory of the Transmission Process in Language Contact. Heidelberg: Winter.

Washburn, Mary, Katherine McKinney-Bock, Erika Varis, Ann SaWyer y Barbara Tomaszewicz (eds.). 2011. Proceedings of the 28th West Coast Conference on Formal Linguistics. Somerville, MA: Cascadilla Proceedings Project.

Willis, ERIK. 2010. Dominican Spanish Intonation. En Pilar Prieto y P. Roseano (eds.), pp. 123-153.

Yasavul, Murat. 2013. Prosody of focus and contrastive topic in K'iche'. OSUWPL 60: 129-160.

ZúÑIga, Fernando. 2007. Mapudungun: El Habla Mapuche. Santiago: Centro de Estudios Públicos. 